\title{
Applicability of Literature Values for Green-Ampt Parameters to Account for Infiltration in Hydrodynamic Rainfall-Runoff Simulations in Ungauged Basins
}

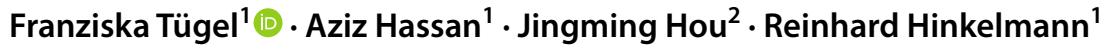

Received: 14 January 2021 / Accepted: 10 July 2021 / Published online: 16 August 2021

(c) The Author(s) 2021

\begin{abstract}
This study aimed to evaluate the suitability of literature parameter values for the Green-Ampt infiltration model to be used in hydrodynamic rainfall-runoff simulations. The outcome of this study supports to decide which literature values should be taken if observed data for model calibration is not available. Different laboratory experiments, a plot-scale experiment in the Thiès catchment in Senegal, and a flash flood in the region of El Gouna in Egypt, have been simulated with the 2D shallow water model Hydroinformatics Modeling System (hms) incorporating the Green-Ampt model. For four test cases with available runoff data, the results of the calibrated models were compared to those obtained from average values after Rawls et al. (Journal of Hydraulic Engineering 1:62-70, 1) and Innovyze (Help documentation of XPSWMM and XPStorm, 2). The results showed a clear underestimation of infiltration in two of three considered laboratory experiments, while for a field experiment in Senegal, average values after Rawls et al. (Journal of Hydraulic Engineering 1:62-70,1) led to a strong overestimation and the ones after Innovyze (Help documentation of XPSWMM and XPStorm, 2) to an underestimation of infiltration. In a case study on flash floods in an ungauged region in Egypt, the values of both sources led to a strong overestimation of infiltration, when the simulation results are compared to observed flooding areas. It can be concluded, that the values after Innovyze (Help documentation of XPSWMM and XPStorm, 2) lead to overall better results than the ones after Rawls et al. (Journal of Hydraulic Engineering 1:62-70, 1). According to the results, the hydraulic conductivity in ungauged areas with bare sandy soil should be reduced by about 90-100\% compared to the value after Rawls et al. (Journal of Hydraulic Engineering 1:62-70, 1).
\end{abstract}

Keywords Robust 2D shallow water model $\cdot$ Hydroinformatics Modeling System $\cdot$ Sensitivity analysis $\cdot$ Ungauged catchments - Automatic calibration

\section{Introduction}

Hydrodynamic models are more and more used to simulate not only the flow and flooding areas of surface waters but also rainfall-induced overland flow in small catchments [3-7], the propagation of flash floods [8-11], and flood inundation in urban areas [12-15]. Additionally, to the calculation of the flow

Franziska Tügel

franziska.tuegel@wahyd.tu-berlin.de

1 Chair of Water Resources Management and Modeling of Hydrosystems, Technische Universität Berlin, Straße des 17. Juni 135, 10623 Berlin, Germany

2 School of Water Resources and Hydro-Power Engineering, Xi' an University of Technology, Xi'an, China field, appropriate methods to represent the runoff generation are needed to establish an integrated hydrological-hydrodynamic model. As 2D shallow water models are typically used for the simulation of relatively short flooding events of some hours up to a few days rather than long-term rainfall-runoff simulations, infiltration represents the most important water loss [16], while evapotranspiration can be neglected in many cases or taken into account in a very simplified way. Infiltration describes the process when rainwater or ponding water is absorbed by the soil. The infiltrated water can either flow further downstream relatively close and parallel to the surface (interflow), be stored in the unsaturated soil zone, or percolate into deeper soil layers and finally contribute to groundwater recharge. For flood modeling it is specifically interesting how much water of the rainfall will lead to overland runoff and how much is "lost" by infiltration. Especially for rural areas and green urban infrastructure, the 
infiltration losses have to be taken into account. A good understanding of infiltration and its representation in models is crucial not only for the appropriate risk management of heavy rainfalls and flash floods but also for successful solutions of water harvesting and groundwater recharge [17]. Concerning the global trends of ongoing urbanization and climate change coming along with more frequent and more intense hydro-meteorological extremes in terms of floods and droughts, damages from inundations on the one hand and lowered groundwater tables and water stress, on the other hand, will increase and get more severe in future $[4,10,18,19]$. To mitigate these effects, so-called watersensitive or climate-adapted urban planning and water resources management strategies considering sustainable urban drainage systems (SUDS) [20, 21] and low impact developments (LIDs) [22-24] are gaining increasing importance. Measures such as infiltration basins, swales, raingardens, or permeable pavement should lead back to a more natural water cycle to mitigate flood risks, store water, enhance evapotranspiration, and stabilize groundwater tables. To investigate the effectiveness of such sustainable stormwater management measures with regard to flood mitigation, an appropriate representation of infiltration in 2D hydrodynamic rainfall-runoff models is also needed.

The infiltration process is influenced by many factors, such as soil texture class, soil moisture, soil surface condition, soil bulk density, content of organic matters and litter in the soil, land cover, land use, topography, rainfall characteristics as well as spatial variability of soil properties [17, 25-28]. It has been, for example, observed that infiltration capacities are usually higher on vegetated than on bare soil surfaces, which is caused among other things by the protection of the surface against the kinetic energy of raindrops preventing the rearrangement of soil particles and thus surface sealing or crust formation. Observations of Ribolzi et al. [29] confirmed the hypothesis that higher effective rainfall intensity was responsible for the formation of less permeable erosion crusts on a $30 \%$ slope than the structural crusts that developed on a $75 \%$ slope. Mohammadzadeh-Habili and Heidarpour [30] carried out column experiments and numerical simulations to study various effects of infiltration into layered soils. If, for example, water infiltrates through an upper layer of finer and less permeable soil than the coarser sublayer, the wetting front, which is usually considered to be stable, becomes unstable forming narrow wetting columns or fingers. Deng and Zhu [31] stated - that similar to saturated flow-the harmonic average of hydraulic conductivities is the best approach to calculate infiltration in layered soils. In their study, they showed that this is true for both, coarse-over-fine and fine-over-coarse layer formations [31]. Assouline and Mualem [17] concluded from their study on heterogeneous small bare catchments, that the impact of surface sealing is much more important than the one of spatial soil variability. Another important factor that can influence infiltration processes is the microtopography, which was, for example, investigated by Esteves et al. [32], Fiedler and Ramirez [33], Mallari et al. [34], Thompson et al. [35], and Xiang et al. [36]. Also, friction can influence infiltration, as higher friction leads to lower flow velocities and more water can infiltrate during the decelerated propagation of the flood wave. Ries et al. [28] conducted 120 experiments with a rainfall simulator on different land covers and soil types with different initial water contents, rain intensities and durations. Based on their observations they stated, that simplified approaches, which are still often applied in models used for the risk management of flash floods-up to the strongest simplification of completely neglecting the runoff reduction during heavy rainfalls-are not suitable. This is shown among others by the fact, that in their conducted experiments even saturated soils still showed significant infiltration rates [28].

There exist many different approaches to model the water losses caused by infiltration, starting from simplified empirical approaches such as the well-known runoff-coefficient, loss-rate, and SCS-CN (Soil Conservation Service Curve Number) methods as well as the Horton equation, more physically-based methods like the Philip infiltration model and the Green-Ampt model, up to the Richards equation. In investigations of Caviedes-Voullième et al. [3], the SCS-CN method was found to be inadequate to be coupled with a distributed model for runoff computations, and as the Richards equation is very complex and the solution needs a lot of computational effort as well as many measured data [37, 38], simplified equations are often used in rainfall-runoff models, where the Green-Ampt model is one of the most popular ones [4, 16, 39, 40]. Developed by Green and Ampt already in 1911 [41], many different applications, modifications, and extensions have been carried out in the last more than 100 years, and in many test cases, it was proven that this model is generally able to appropriately represent infiltration processes [16, 42-44].

The main problem for real-world applications consists in estimating the Green-Ampt parameters, namely the hydraulic conductivity, capillary suction head at the wetted front, and effective porosity (representing the saturated soil water content), additionally to the initial soil water content of the soil. The capillary suction in the fine pores of a soil dominates the infiltration process in dry soils, especially at the beginning of a rainfall event, if there is an initial soil moisture deficit which is expressed as difference between saturated and initial soil water content. With increasing water saturation of the soil, the capillary suction reduces and drops to zero, if the soil is completely saturated with water. Then the infiltration depends only on gravity and the infiltration rate is usually assumed to be equal to the saturated hydraulic conductivity [45]. For simple test cases or laboratory experiments, the Green-Ampt parameters might be measured directly, but due to the high effort and costs, 
it is usually not feasible to directly measure the needed soil properties at enough locations within large areas as it would be needed for real-world applications [46, 47]. If available runoff and sometimes even infiltration time series exist, the Green-Ampt parameters can be considered as calibration parameters $[6,16,43]$. As also observed runoff data is often not available for real-world applications, e.g., considering flash floods or ungauged catchments, the Green-Ampt parameters have to be estimated based on relations to more easily available soil properties such as the soil texture class. Many different of such methods have been developed over the past decades. The probably best known and most cited contribution is the study of Rawls et al. [1], where they developed a table of parameter sets in dependence on soil texture class and soil horizon. These average parameter values are the result of analyzing 5000 soil horizons in the USA, for which the Green-Ampt parameters were derived from the Brooks and Corey parameters that were fitted before to the available water retention data. For a more accurate estimation than taking those average values for the given soil texture class and if more detailed soil information is available, they recommend to predict the water retention matrix potential curve by a regression equation based on particle size distribution, organic matter, bulk density, and 0.33 bar and 15 bar moisture retention values. The best option, of course, would be to determine the Green-Ampt parameters based on measured water retention matrix potential data [1], but as mentioned before this is usually too costly and too much effort for large areas in real-world applications. Other typical values for the Green-Ampt parameters are, for example, presented in the manual of the modeling software company Innovyze [2], referring to different sources, where the hydraulic conductivity is based on minimum infiltration rates observed from measured rainfall, runoff and infiltrometer data, and the initial soil moisture deficit is given for dry conditions as typical moisture deficit at the wilting point, which should be decreased for moist or very wet antecedent conditions [2]. Furthermore, there have been several studies on finding suitable regression equations, where the Green-Ampt parameters can be derived from more easily measured parameters such as percentages of clay, sand, gravel, and the bulk density [36], or from the percentage of surface cover and crusting or initial soil moisture and antecedent rainfall [48].

Especially, on bare soils with no vegetation, the kinetic energy of raindrops can disturb and rearrange soil aggregates resulting in the formation of a surface crust or sealing [49-51]. Such layers can lead to a significant decrease in the infiltration capacity by 20 to 2000 times $[52,53]$. The thickness of such layer has been reported to vary from 1 to 5 $\mathrm{mm}[53,54]$. Different adaptions and extensions of infiltration models to account for the effects of a surface crust have been developed $[17,55]$. A very simple one is a modified
Green-Ampt model, where the hydraulic conductivity is calculated as effective hydraulic conductivity of the crust and subcrust soil [17, 32, 51, 56].

For practical applications, tabulated standard parameters depending on the soil texture class as represented by Rawls et al. [1] or Innovyze [2] are very interesting and might sometimes be assumed without further knowledge about the actual infiltration behavior, especially when investigating ungauged areas. As these tabulated parameter values are derived from a limited number of field and lab experiments with soils from limited areas, and as it is not clear whether these literature values represent a good assumption of the actual infiltration in larger-scale rainfall-runoff simulations, further analysis is desirable. This study aims to analyze the applicability of tabulated values from two different literature sources to consider infiltration with the Green-Ampt model in 2D shallow water models. Recommendations should be given for rainfall-runoff simulations in ungauged areas in terms of in which cases the tabulated values of which source are suitable to estimate infiltration or giving tendencies how to adapt them. After describing the applied methods, the characteristics and setups of different test cases with measured data are represented. For one test case, a sensitivity analysis is carried out to study the effects of different parameters on infiltration. Afterwards, the results of several simulations with different parameter sets are presented for each test case to evaluate the performance of the model when taking into account the average parameter values compared to the calibrated ones. Three of the test cases are laboratory experiments and one is a field experiment on a small plot in the Thiès catchment in Senegal, where also the extension for crusted soils is exemplarily taken into account to evaluate its effect. Finally, a case study on flash floods in an ungauged desert region in Egypt is shown and the plausibility of the results based on the average values for the Green-Ampt parameters and the impact of a surface crust and friction on infiltration is analyzed.

\section{Material and Methods}

\subsection{D Shallow Water Model for Overland Flow}

The Hydroinformatics Modelling Sytem (hms) is used to simulate the flow field in terms of flow velocities and water depths. It is a Java-based flexible and extendable modeling framework, which has been developed at the Chair of Water Resources Management and Modeling of Hydrosystems of the Technische Universität Berlin, Germany. Previous studies using hms have been carried out, for example, by Hassan et al. [57], Özgen et al. [58], Simons [59], and Tügel et al. [11]. In hms, the depth-averaged 2D shallow water equations are solved with an explicit cell-centered finite volume 
method, and incorporates robust numerical methods such as the HLLC Riemann solver and a sophisticated total variation diminishing method (TVD) to deal with the numerical challenges, which are associated, for example, with the simulation of very small water depths over complex topography or propagating wet-dry fronts [6]. The general form of the 2D conversation law can be expressed as follows:

$\frac{\partial \mathbf{q}}{\partial t}+\frac{\partial \mathbf{f}}{\partial x}+\frac{\partial \mathbf{g}}{\partial y}=\mathbf{s}$,

where $\mathbf{q}$ is the vector of conserved state variables, $t$ is the time, $\mathbf{f}$ and $\mathbf{g}$ denote the vectors of advective and diffusive fluxes in $\mathrm{x}$ - and $\mathrm{y}$-direction, respectively, and the vector $\mathbf{s}$ represents the source terms. This equation describes mathematically, that a temporal change of the conserved variables in the control volume can only be caused by a net flux over the surface of the control volume and/or by sinks/sources within the control volume. Inserting the following vectors in the general conservation law (Eq. 1) yields in the shallow water equations (Eq. 2):

$$
\begin{gathered}
\mathbf{q}=\left[\begin{array}{c}
h \\
u h \\
v h
\end{array}\right], \quad \mathbf{f}=\left[\begin{array}{c}
u h \\
u u h+g h^{2} / 2 \\
u v h
\end{array}\right], \\
\mathbf{g}=\left[\begin{array}{c}
v h \\
v u h \\
v v h+g h^{2} / 2
\end{array}\right] \mathbf{s}=\left[\begin{array}{c}
r \\
-g h \frac{\partial z_{B}}{\partial x}-\mathrm{s}_{\mathrm{f}, \mathrm{x}} \\
-g h \frac{\partial z_{B}}{\partial y}-s_{\mathrm{f}, y}
\end{array}\right] .
\end{gathered}
$$

Here, the first row of each vector contains the mass balance equation and the second and third rows represent the momentum balance equations in $\mathrm{x}$ - and $\mathrm{y}$-direction, respectively. $\mathrm{h}$ is the water depth, $\mathrm{u}$ and $\mathrm{v}$ are the velocity vector components in $\mathrm{x}$ - and $\mathrm{y}$-direction, respectively, and $\mathrm{z}_{\mathrm{B}}$ is the bottom elevation above datum. uh and vh represent the specific discharge in $\mathrm{x}$ - and $\mathrm{y}$-direction, respectively. $\mathrm{r}$ is a mass source/sink term accounting for precipitation, infiltration or injection/abstraction of water, and g denotes the gravitational acceleration. The bottom slope terms are $-g h \frac{\partial z}{\partial x}$ and $-g h \frac{\partial z}{\partial y}$ and the momentum sinks due to bottom friction are denoted with $\mathrm{s}_{\mathrm{f}, \mathrm{x}}$ and $\mathrm{s}_{\mathrm{f}, \mathrm{y}}$ in $\mathrm{x}$ - and $\mathrm{y}$-direction, respectively. The well-known friction law after Manning was used for test cases 2 and 3 as well as for the case study about flash floods in El Gouna:

$\mathrm{s}_{\mathrm{f}, \mathrm{x}}=\frac{g \cdot n^{2}}{h^{\frac{1}{3}}} u \sqrt{u^{2}+v^{2}}, s_{\mathrm{f}, \mathrm{y}}=\frac{g \cdot n^{2}}{h^{\frac{1}{3}}} v \sqrt{u^{2}+v^{2}}$,

where $\mathrm{n}$ denotes the Manning roughness coefficient. In the test case 4, the depth-dependent Manning 's coefficient after Jain et al. [60] was used, as Mügler et al. [5] showed that the application results in the best representation of the velocity field for the considered area: $n(h)= \begin{cases}n_{0}{\frac{h}{h_{0}}}^{-\varepsilon} & \text { for } h<h_{0} \\ n_{0} & \text { for } h \geq h_{0},\end{cases}$

where $\mathrm{n}(\mathrm{h})$ denotes the depth-dependent Manning 's friction coefficient, $n_{0}$ the minimum land surface-dependent Manning's friction coefficient corresponding to flow depth $h_{0}$ beyond which $\mathrm{n}$ is assumed to be constant, and $\varepsilon$ is a parameter accounting for drag due to vegetation.

As laminar flow conditions were proven in the laboratory experiment after Smith and Woolhiser [61], the laminar friction law as described in Smith and Woohlhiser (1971) and Delfs et al. [62], was used in the first test case:

$\mathrm{s}_{\mathrm{f}, \mathrm{x}}=\frac{g}{C_{\mathrm{lam}}{ }^{2} h^{3} \frac{\partial z_{B}}{\partial x}} u \sqrt{u^{2}+v^{2}}, s_{\mathrm{f}, y}=\frac{g}{C_{\mathrm{lam}}{ }^{2} h^{3} \frac{\partial z_{B}}{\partial y}} v \sqrt{u^{2}+v^{2}}$,

where $C_{\text {lam }}$ denotes the laminar friction coefficient. The general form of the balance equation is discretized with a cell-centered finite volume method in space and the forward Euler method in time to calculate the conserved variables at the next time step $\mathbf{q}^{\mathrm{n}+1}$ as follows:

$\mathbf{q}^{\mathrm{n}+1}=\mathbf{q}^{\mathrm{n}}-\frac{\Delta t}{A} \sum_{k=1}^{n_{b}} \mathbf{F}_{k}^{n} \mathbf{n}_{k} l_{k}+\Delta t \mathbf{s}^{\mathrm{n}}$,

where $\mathrm{n}+1$ and $\mathrm{n}$ denote the new and the old time level, respectively, $\Delta \mathrm{t}$ is the time step and $\mathrm{A}$ the area of the considered cell. $\mathbf{F}$ denotes the vector of advective and diffusive fluxes over the edge $\mathrm{k}$ of the considered cell, $n_{b}$ is the number of cell edges, $\mathbf{n}$ is the normal vector pointing outward of a face, and $\mathbf{l}$ is the length of a face. $\mathbf{s}$ denotes the source vector at time level $\mathrm{n}$, while for the friction source term the splitting point-implicit method is used to avoid numerical instabilities. A more detailed description can be found in [59].

\subsection{Green-Ampt Model for Infiltration}

To calculate the mass sink due to infiltration, the Green-Ampt model is used, in which the cumulative infiltration and the infiltration rate are calculated with the following equations:

$F(t)=K t+\left(h_{0}-h_{\mathrm{f}}\right) \Delta \theta \ln \left(1+\frac{F(t)}{\left(h_{0}-h_{\mathrm{f}}\right) \Delta \theta}\right)$,

$f(t)=K\left(1+\frac{\left(h_{0}-h_{\mathrm{f}}\right) \Delta \theta}{F(t)}\right)=\frac{d F}{d t}$,

where $F(t)$ denotes the cumulative depth of infiltration, $f(t)$ the infiltration rate, $\mathrm{K}$ the hydraulic conductivity at residual air saturation; according to Whisler and Bouwer [63], $\mathrm{K}$ is assumed to be $50 \%$ of the saturated hydraulic conductivity 
$K_{s} . h_{\mathrm{f}}$ is the wetted front capillary suction head, and $h_{0}$ is the ponding water depth, which is provided by the surface runoff calculation. $\Delta \theta$ denotes the soil moisture deficit, which is the difference between the saturated soil water content $\theta_{\mathrm{s}}$, usually considered with the effective porosity $n_{\text {eff }}$, and the initial moisture content $\theta_{\mathrm{i}}$. The wetted front capillary suction head, effective porosity, and hydraulic conductivity are called Green-Ampt parameters. The infiltration rate is calculated for each cell and time step depending on the water depth and water saturation of the soil of the previous time step in the considered cell. The calculated infiltration rates for all cells are then taken into account as mass sinks in the mass balance equation (see $r$ in Eq. 2, vector $\mathbf{s}$, first row), while rainfall is represented by a mass source.

When the considered soil tends to generate a surface crust of lower hydraulic conductivity, Brakensiek and Rawls [55] proposed to calculate the effective hydraulic conductivity of a two-layer soil—crust and subcrust—by a harmonic mean [56]:

$K_{\mathrm{e}}= \begin{cases}K_{\mathrm{e}} & \text { for } \mathrm{Z}_{\mathrm{f}} \leq \mathrm{Z}_{\mathrm{c}} \\ \frac{\mathrm{Z}_{\mathrm{f}}}{{\frac{\mathrm{z}}{\mathrm{f}}-\mathrm{Z}_{\mathrm{c}}}_{K}+\frac{\mathrm{Z}_{\mathrm{c}}}{K_{\mathrm{c}}}} & \text { for } \mathrm{Z}_{\mathrm{f}}>\mathrm{Z}_{\mathrm{c}},\end{cases}$

where $K_{e}$ is the effective hydraulic conductivity, $\mathrm{K}_{\mathrm{c}}$ is the hydraulic conductivity of the crust, $\mathrm{K}$ is the hydraulic conductivity of the subcrust soil as used in Eqs. 7 and 8. $Z_{c}$ is the crust thickness, and $Z_{\mathrm{f}}$ denotes the wetted depth which is calculated by the cumulative infiltration depth from the previous time step divided by the soil moisture deficit. Furthermore, they proposed an equation for the prediction of the steady-state crust conductivity depending on tabled values for a reduction factor for the subcrust conductivity, and the steady state matric potential drop at the crust/subcrust interface (Eq. 10). For more details on this approach, the reader is referred to Rawls et al. [56].

$K_{\mathrm{e}}=\frac{S C}{1+\Psi_{\mathrm{i}} / L} \cdot K_{\mathrm{s}}$ where SC denotes the reduction factor for subcrust conductivity, $\Psi_{\mathrm{i}}$ stands for the steady state capillary potential drop at the crust/subcrust interface, and $K_{s}$ is the saturated subcrust conductivity, which was set in this study to the same values as the hydraulic conductivity of the subcrust soil as given in the literature values for Green-Ampt parameter K. The approach of calculating the effective conductivity in unsaturated layered soils with a thickness-weighted harmonic average has been considered as suitable approach in several studies $[31,64,65]$. But in formations with fine soil over coarse layers, non-piston flow might be dominating, which is not included in the simplifications of the Green-Ampt model. Zhu and Warrick [65] observed that the harmonic average tends to overestimate infiltration in these cases. Nevertheless, we applied this simplified approach given in Eqs. 9 and 10 , to evaluate its performance in our cases.

\subsection{Literature Values of Green-Ampt and Crust Parameters}

Rawls et al. [1] analyzed different soils and determined average Green-Ampt parameters based on soil texture classes, where seven of them are shown in Table 1.

Other values are, for example, given in the help documentation of the hydraulic and hydrologic modeling software XPStorm and XPSWMM of the Innovyze company [2]. The values for seven different soil texture classes are given in Table 2.

They refer to typical values for the minimum (asymptotic) infiltration rate corresponding to the saturated hydraulic conductivity for different soil texture classes after Akan [67], which were determined from measured rainfall, runoff and infiltrometer data [68, 69], typical values for the average capillary suction head from several published values, as well as typical values for the initial soil moisture deficit at wilting point [66]. The authors state that these values for the initial soil moisture deficit would apply for very dry conditions, and lower values
Table 1 Average values and ranges of the Green-Ampt parameters after Rawls et al. [1]

\begin{tabular}{llcc}
\hline Texture class & Effective porosity $n_{\text {eff }}(-)$ & $\begin{array}{l}\text { Capillary suction at wetted } \\
\text { front } h_{\mathrm{f}}(\mathrm{cm})\end{array}$ & $\begin{array}{l}\text { Hydraulic } \\
\text { conductivity K } \\
(\mathrm{cm} / \mathrm{h})\end{array}$ \\
\hline Sand & $0.417(0.354-0.480)^{*}$ & $4.95(0.97-25.36)^{* *}$ & 11.78 \\
Loamy sand & $0.401(0.329-0.473)$ & $6.13(1.35-27.94)$ & 2.99 \\
Sandy loam & $0.412(0.283-0.541)$ & $11.01(2.67-45.47)$ & 1.09 \\
Loam & $0.434(0.334-0.534)$ & $8.89(1.33-59.38)$ & 0.34 \\
Sandy clay loam & $0.330(0.235-0.425)$ & $21.85(4.42-108.0)$ & 0.15 \\
Clay loam & $0.309(0.279-0.501)$ & $20.88(4.79-91.10)$ & 0.10 \\
Clay & $0.385(0.269-0.501)$ & $31.63(6.39-156.5)$ & 0.03 \\
\hline
\end{tabular}

*Numbers in parentheses: one standard deviation around the average

**Antilog of the $\log$ mean and standard deviation 
Table 2 Typical values of Green-Ampt parameters given in Innovyze [2]

\begin{tabular}{llll}
\hline Texture class & $\begin{array}{l}\text { Typical initial moisture } \\
\text { deficit at wilting point }(-)\end{array}$ & $\begin{array}{l}\text { Capillary suction at } \\
\text { wetted front } h_{\mathrm{f}}(\mathrm{cm})\end{array}$ & $\begin{array}{l}\text { Hydraulic } \\
\text { conductivity K } \\
(\mathrm{cm} / \mathrm{h})\end{array}$ \\
Reference & Clapp and Hornberger [66] & several sources & Akan [67] \\
\hline Sand & 0.34 & 10.16 & $0.76-1.14$ \\
Loamy sand & - & - & $0.76-1.14$ \\
Sandy loam & 0.33 & 20.32 & $0.76-1.14$ \\
Loam & 0.31 & 20.32 & $0.38-0.76$ \\
Sandy clay loam & 0.26 & - & $0.13-0.38$ \\
Clay loam & 0.24 & 25.40 & $0.00-0.13$ \\
Clay & 0.21 & 17.78 & $0.00-0.13$ \\
\hline
\end{tabular}

should be used when wetter initial conditions occur. When comparing these values with the ones after Rawls et al. [1], it is striking that for sand the maximum value for the hydraulic conductivity after Akan [67] is about one order of magnitude lower, and roughly halved for loamy sand, but approximately doubled for loam, while the maximum value for sandy loam and the minimum value for loam after Akan [67] are very similar to the ones after Rawls et al. [1]. For sandy clay loam the minimum value and for clay loam the maximum value after Akan [67] are very similar to those after Rawls et al. [1], and for clay the value after Rawls et al. [1] is closer to the minimum value after Akan [67]. The average capillary suction head after Akan [67] is higher than after Rawls et al. [1] for all texture classes except clay.

Considering a crust with Eq. 10 for $K_{\mathrm{e}}$, Rawls et al. [56] determined the reduction factor for the subcrust conductivity and the steady state matric potential drop at the crust/subcrust interface depending on the soil texture class as shown in Table 3.

\subsection{Sensitivity Analysis}

For the test case in the Thiès catchment in Senegal, a sensitivity analysis of the Green-Ampt parameters, the crust parameters, and the friction parameters is carried out to see their effects on the runoff hydrograph. For the Green-Ampt parameters the values after Rawls et al. [1] for loamy sand

Table 3 Reduction factor for the subcrust conductivity and the mean steady state matric potential drop at the crust/subcrust interface [56]

\begin{tabular}{lll}
\hline Soil texture & $\begin{array}{l}\text { steady-state matric poten- } \\
\text { tial drop at crust/subcrust } \\
\text { interface } \Psi_{\mathrm{i}}(\mathrm{cm})\end{array}$ & $\begin{array}{l}\text { Reduction factor of } \\
\text { subcrust conductivity } \\
\text { SC }(-)\end{array}$ \\
\hline Loamy sand & 3 & 0.89 \\
Sandy loam & 6 & 0.86 \\
Loam & 7 & 0.82 \\
Clay & 9 & 0.75 \\
\hline
\end{tabular}

are used for the reference case, and each parameter value is varied one after another to be set to the values for sand and sandy loam after Rawls et al. [1] (Table 1). For the crust approach after Eq. 9, the crust conductivity is varied between the values for loam, sandy clay loam and clay loam after Rawls et al. [1], and the crust thickness is varied between 2, 5 and $10 \mathrm{~mm}$. For the crust approach after Eq. 10, the tabled values after Rawls et al. [56] (Table 3) for sand, loamy sand, and sandy loam are compared. For the friction parameters, the calibrated values after Simons [59] are used for the reference case and are varied within reasonable ranges or set to much higher values, to see that a significant effect is only visible, when using parameter values out of reasonable ranges.

\subsection{Optimization Techniques}

Especially, if several parameters need to be calibrated, automatic calibration is required as a manual calibration would be very time-consuming, because many simulations have to be carried out varying all calibration parameters sequentially, and possible dependencies between several parameters have to be considered as well. Automatic calibration makes use of an optimization algorithm, to find the optimum parameter combination as fast as possible. Several simulations with varying parameter values are carried out automatically, where the ranges for each parameter can be defined by the user. To carry out an automatic calibration of the Green-Ampt parameters and in some cases also initial water content and the friction within predefined ranges, optimization techniques that are implemented in the SciPy package optimization were used in this study. For the results presented in this work, the simplicial homology global optimization (SHGO) algorithm was used [70]. Within this algorithm, the global minimum of a chosen objective function is searched by varying the different calibration parameters within predefined reasonable ranges. The well-known Nash-Sutcliffe efficiency [71] as well as the nonparametric Kling-Gupta efficiency [72], which are both included in the PyPI package hydroeval [73], were used as objective functions: 
$N S E=1-\frac{\Sigma\left(Q_{\text {sim }}-Q_{\text {obs }}\right)^{2}}{\Sigma\left(Q_{\text {obs, mean }}-Q_{\text {obs }}\right)^{2}}$,

where NSE denotes the Nash-Sutcliffe efficiency, $Q_{\text {sim }}$ and $\mathrm{Q}_{\mathrm{obs}}$ are the simulated and observered discharge values at different times respectively, and $\mathrm{Q}_{\mathrm{obs} \text {, mean }}$ is the mean value of the observed values.

$K G E_{\mathrm{np}}=1-\sqrt{(\beta-1)^{2}+\left(\alpha_{\mathrm{np}}-1\right)^{2}+\left(r_{\mathrm{s}}-1\right)^{2}}$,

where $K G E_{\mathrm{np}}$ is the nonparametric Kling-Gupta efficiency, $\beta$ denotes the bias between simulated and observed mean discharge calculated as simulated mean divided by observed mean, $\alpha_{\mathrm{np}}$ is the nonparametric form of the discharge variability, and $r_{\mathrm{s}}$ the nonparametric correlation term, calculated with the Spearman rank correlation on the ranks of the observed and simulated discharge time series. For both indicators NSE and $K G E_{\text {np }}$ - a value of one would express a perfect fit of simulated to observed discharges. Within the optimization algorithm, the calibration parameters are varied to reach the minimum of the combined error from NSE and $K G E_{\mathrm{np}}$ :

error $=(1-N S E)+\left(1-K G E_{\mathrm{np}}\right)$.

\subsection{Experimental Setups and Study Areas}

Four different test cases with available data for calibration and one case study about flash floods in the ungauged area of El Gouna, Egypt are investigated. The basic information on each case is summarized in Table 4 and the experimental setups (Test 1-4) and study area characteristics (Case study El Gouna) are briefly described in the following sections.

\subsubsection{Test Case 1 - Laboratory Experiment after Smith and Woolhiser [61]}

As a first test case, the well-known rainfall-runoff experiment of Smith and Woolhiser [61] was chosen. They equipped a laboratory-scale soil flume of $12.2 \mathrm{~m}$ length, $0.051 \mathrm{~m}$ width, $1.22 \mathrm{~m}$ depth with river-deposit sand (Poudre fine sand) and porous flume ends to collect the seepage water to get a prototype infiltrating slope (Fig. 1). To create artificial rainfall, they installed drop-producing manifolds, and to prevent splash erosion, the soil surface was covered with gauze. In the considered experiments, the adjustable slope was set to $1 \%$. The runoff was measured continuously by a pressure transducer and to observe the moving soil moisture front, gamma-ray attenuation was used. The soil properties were experimentally determined. Through comparison of the observed surface runoff hydrograph and simulations with their coupled model of the one-dimensional Richards equation for infiltration and the kinematic-wave model for overland flow (solved with the finite-difference method), they figured out that the observed data were fitted well when a laminar friction law was taken into account in the model (see Eq. 5).

\subsubsection{Test Cases 2 and 3 - Laboratory Experiments after Lima [74]}

As the second and third test cases, two laboratory experiments after Lima [74] were chosen. A soil flume according to Fig. 1 of $1 \mathrm{~m}$ length, 0.5 width, $0.08 \mathrm{~m}$ depth, a slope of $10 \%$, and with percolated metal plates at the bottom to collect the percolation water was used together with a programmable rainfall simulator to carry out rainfall-runoff experiments with different soils. The first soil was a loam collected from Limburg in the Netherlands (Test 2) and the second soil was a clay loam collected from Alentejo in Portugal (Test 3). The initial and saturated soil water contents as well as the average particle densities and average soil bulk densities were measured by Lima, other parameters such as the hydraulic conductivities were estimated.

\subsubsection{Test Case 4 - Field Experiment in Thiès Catchment, Senegal [75]}

The field experiment on a plot of $10 \mathrm{~m} \mathrm{x} 4 \mathrm{~m}$ within the Thi 'es catchment in Senegal (14\%4 '43”'N, 16 $53^{\circ}$ '16”'W) was considered as the last test case (Fig. 2). The details of the experimental setup are presented in Tatard et al. [75], and

Table 4 Overview of studied test cases

\begin{tabular}{lllllll}
\hline Case & Source & Type & Texture class & Extent $\left(\mathrm{m}^{2}\right)$ & Slope $(\%)$ & Rainfall data \\
\hline Test 1 & Smith and Woolhiser [61] & Lab experiment & Fine sand & $12.200 \times 0.051$ & 1 & $4.2 \mathrm{~mm} / \mathrm{min} 15 \mathrm{~min}$ \\
Test 2 & Lima [74] & Lab experiment & Loam & $1.0 \times 0.5$ & 10 & $2.25 \mathrm{~mm} / \mathrm{min} 15 \mathrm{~min}$ \\
Test 3 & Lima [74] & Lab experiment & Clay loam & $1.0 \times 0.5$ & 10 & $2.25 \mathrm{~mm} / \mathrm{min} 15 \mathrm{~min}$ \\
Test 4 & Tatard et al. [75] & Field test Senegal & Sand & $10 \times 4$ & 1 & Time series $86 \mathrm{~min}$ \\
Case study & Tügel et al. [11] & Flash flood & Sand & $9000 \times 11000$ & 0.5 & Time series 10.3 hours \\
& & ungauged area, & & & \\
& & Egypt & & & \\
\hline
\end{tabular}


Fig. 1 Sketch of soil flume of the laboratory experiments in Test cases 1,2 and 3

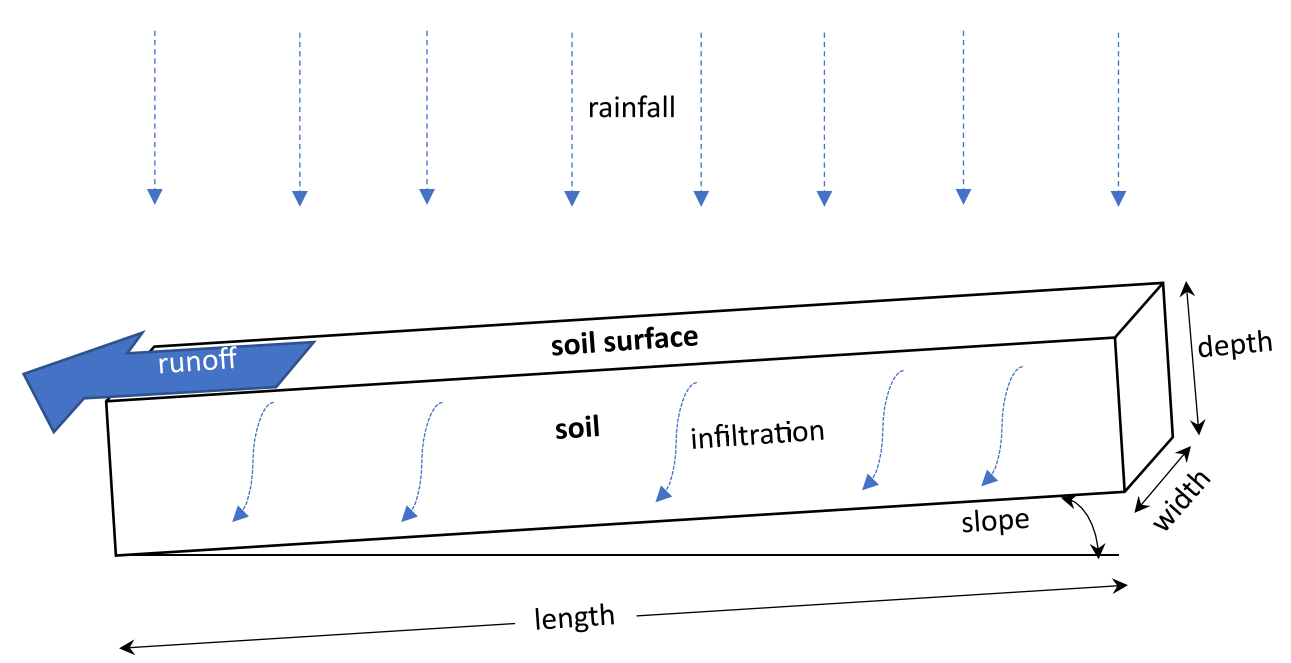

Mügler et al. [5], while Simons et al. [6] already presented previous simulations with hms and the Green-Ampt model. The plot consisted of sandy soil and the average slope was approximately $1-1.5 \%$. Rainfall-runoff tests have been carried out by using a rainfall simulator.

\subsubsection{Case Study-Flash Flood Simulations in El Gouna, Egypt}

El Gouna is a touristic town in the Eastern Desert of Egypt. Although the climate is extremely dry, from time to time strong rainfall events especially in the mountainous areas can generate fast and devastating flash floods, as the usually dry wadi systems turn into rivers with very fast flows. Many settlements, infrastructure, and cities have been constructed inside those usually dry wadi catchments. During flash flood events, these areas are strongly affected and the flooding can cause severe damages to the environment, infrastructure, and properties, and in the worst-case endanger human lives. Consequently, the areas have to face economic, ecological, and social problems due to flash floods. In case of a flood, some streams reach El Gouna, and others drain into the Red Sea north of El Gouna. Heavy rainfall that generates flash floods in the region of El Gouna occurs sporadically in the winter half-year between October-April and often comes from the direction of the Red Sea. Several flash floods and resulting infrastructure damages have been reported in the recent years, e.g. in December 2010, March 2014, October 2015, and October 2016, where total rainfall amounts of approximately $7,34,10$, and $20 \mathrm{~mm}$, respectively, have been observed by satellite data (for the event in 2010) or recorded by the weather station in El Gouna (for events in 2014, 2015,
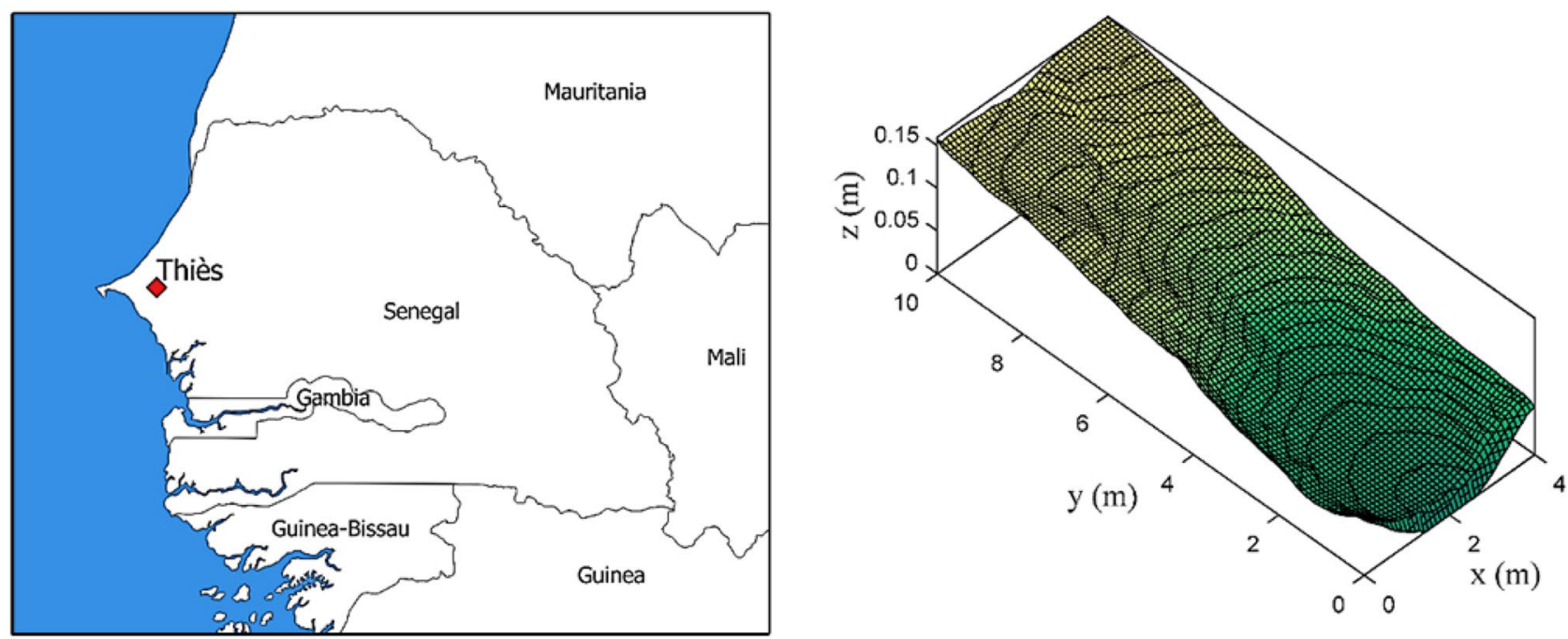

Fig. 2 Left: Location of the Thiès catchment in Senegal (made with Natural Earth), right: elevation of the tested basin [76] 
and 2016) [77]. As a very exceptional occasion, manual discontinuous velocity measurements and corresponding discharge estimations could have been carried out during the flash flood event in March 2014, and are published in Hadidi [78]. Figure 3 represents the location of El Gouna in Egypt, the topography, catchment boundary and streams of Wadi Bili until the point where the velocity measurements have been carried out in 2014, and the detail of the model domain of El Gouna between the measurement point in the Wadi Bili catchment and the Red Sea.

\subsection{Procedure and Numerical Model Setups}

For the four test cases with available data for calibration (4), simulations with different parameter sets are carried out:

- With average values for the Green-Ampt parameters for the given soil after Rawls et al. [1] (see Table 1 for parameter values) to check the performance if these values would be taken without calibration in case of ungauged areas.

- With optimum parameters values as result of the automatic calibration, where the ranges are set for the given soil type after Rawls et al. [1] according to Table 1, and/ or within larger ranges (for example, the combined ranges of two consecutive soil types) to reach the best fit between model and observations within reasonable ranges.

- If available: with parameters values that were derived from direct measurements or calibration given in the literature corresponding to the experiments to check the performance when only the remaining unknown parameters are calibrated.
- With typical values for the Green-Ampt parameters after the help documentation from Innovyze [2] (see Table 2) to check their performance if these values would be taken without calibration in case of ungauged areas.

- In Test 4: exemplarily considering a thin surface crust of lower hydraulic conductivity with the approaches given in Eqs. 9 and 10, as infiltration with the parameters after Rawls strongly overestimate infiltration and as surface sealing may occur on bare soils during heavy rainfalls.

The runoff hydrographs from different parameter sets are evaluated through comparison to the observed ones. Additionally, a case study with flash flood simulations in Egypt is represented under consideration of different values for the infiltration and friction parameters, analyzing the plausibility of the results and the effect of friction and surface crusts on the infiltration processes. Table 5 gives an overview of the model setups and the overall ranges for friction and Green-Ampt parameters covering all ranges of different optimization and simulation runs for each case. The subsequent sections briefly describe the setup of each case.

\subsubsection{Test Case 1 - Laboratory Experiment after Smith and Woolhiser [61]}

The domain was discretized in rectangular cells of $1 \mathrm{~cm} \mathrm{x}$ $1 \mathrm{~cm}$ leading to 6100 cells, and all boundaries were defined as open. Artificial rainfall with a rate of $4.2 \mathrm{~mm} / \mathrm{min}(252$ $\mathrm{mm} / \mathrm{h}$ ) was imposed over 15 minutes, and the total simulation time was set to 17 minutes. The initial conditions for water depths and flow velocities were set to zero. From the initial soil moisture profile measured by Smith and
Fig. 3 Location of El Gouna and the Wadi Bili catchment in Egypt, topography (AW3D30 (CJaxa), and streams in the Wadi Bili catchment and model domain for the area of El Gouna as well as the location of discharge measurements in 2014 published in Hadidi [78] (map: ()OpenStreetMap contributors)

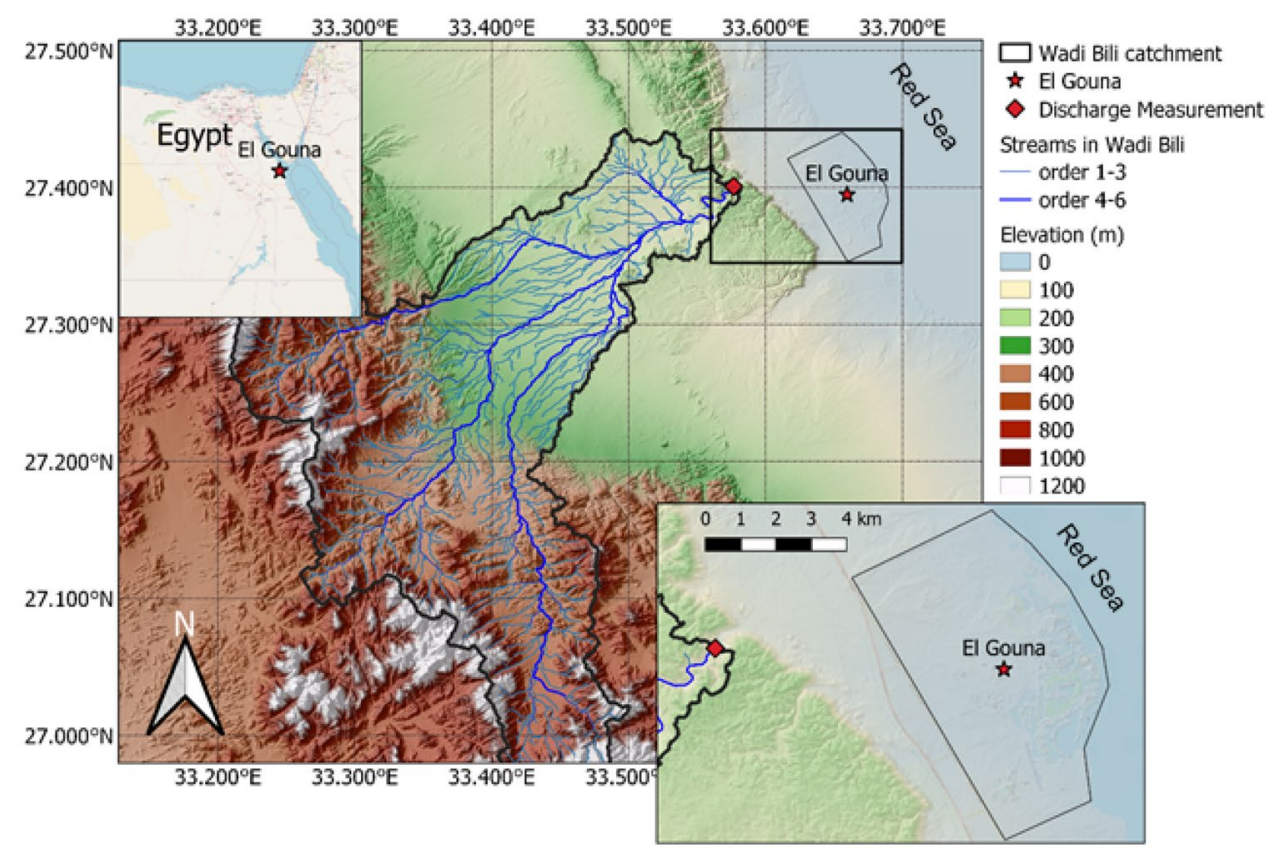


Table 5 Overview of model setups and parameter ranges used during the calibration process

\begin{tabular}{|c|c|c|c|c|c|c|c|}
\hline \multirow[t]{2}{*}{ Case } & \multirow[t]{2}{*}{ Cell size $(\mathrm{m})$} & \multirow[t]{2}{*}{ Sim. time } & \multirow[t]{2}{*}{ Friction law } & \multicolumn{4}{|c|}{$\begin{array}{l}\text { Overall ranges for friction and GA parameters* (varied in different opti- } \\
\text { mization/simulation cases) }\end{array}$} \\
\hline & & & & Friction & $\Delta \theta\left(\mathrm{m}^{3} / \mathrm{m}^{3}\right)$ & $\mathrm{K}(\mathrm{cm} / \mathrm{h})$ & $\mathrm{hf}(\mathrm{cm})$ \\
\hline Test 1 & 0.01 & $17 \mathrm{~min}$ & $C_{\text {lam }}\left(\mathrm{m}^{-1} \mathrm{~s}^{-1}\right)$ Eq. 5 & $1.3 \cdot 10^{6}-1.4 \cdot 10^{6}$ & $0.203-0.480$ & $2.99-11.78$ & $0.97-27.94$ \\
\hline Test 2 & 0.05 & $17 \mathrm{~min}$ & Manning $\left(\mathrm{sm}^{-1 / 3}\right)$ Eq. 3 & $0.010-0.033$ & $0.310-0.523$ & $0.34-0.76$ & $1.33-59.38$ \\
\hline Test 3 & 0.05 & $17 \mathrm{~min}$ & Manning $\left(\mathrm{sm}^{-1 / 3}\right)$ Eq. 3 & $0.012-0.033$ & $0.204-0.495$ & $0.04-0.13$ & $4.79-91.10$ \\
\hline Test 4 & 0.10 & $86 \min$ & Manning depth-depend. Eq. 4 & $\begin{array}{l}n_{0}: 0.014 \mathrm{sm}^{-1 / 3} \\
h_{0}: 4.5 \mathrm{~mm} \varepsilon: 0.1\end{array}$ & $0.154-0.480$ & $0.94-11.78$ & $0.97-25.36$ \\
\hline & & & & & $\begin{array}{l}\text { Crust: } \\
\mathrm{Z}_{\mathrm{c}}: 5 \mathrm{~mm}, \mathrm{~K}_{\mathrm{c}}: 0.39 \mathrm{~cm} / \mathrm{h}\end{array}$ & & \\
\hline Case study & 15.0 & $43 \mathrm{~h}$ & Manning $\left(\mathrm{sm}^{-1 / 3}\right)$ Eq. 3 & $0.01-0.02$ & $\begin{array}{l}0.404-0.387 \\
\text { Crust: } \\
\mathrm{Z}_{\mathrm{c}}: 5 \mathrm{~mm}, \mathrm{~K}_{\mathrm{c}}: 0.03 \mathrm{~cm} / \mathrm{h}\end{array}$ & $0.34-11.78$ & $4.95-8.89$ \\
\hline
\end{tabular}

*based on the ranges given in Rawls et al. [1] and Innovyze [2] (see Section 2.3) for the given soils according to Table 3

Woolhiser [61], an average initial saturation of $S_{\mathrm{i}}=0.2 \mathrm{can}$ be assumed as the initial condition for the soil, which was transferred here into the initial soil water content by multiplying it with the effective porosity : $\theta_{i}=S_{\mathrm{i}} \cdot n_{\text {eff }}$ (neglecting the residual water content), which therefore depends on the assumed saturated soil water content, namely the effective porosity. In one optimization case, the initial and saturated water contents have been used as independent calibration parameters, while in the other cases they were changed together to keep the initial saturation of 0.2. Except for one optimization case, the friction coefficient $C_{\text {lam }}$ was set to the value of $1333333 \mathrm{~m}^{-1} \mathrm{~s}^{-1}$ according to Delfs et al. [62].

\subsubsection{Test Cases 2 and 3 - Laboratory Experiments after Lima [74]}

The domain was discretized in rectangular cells of $5 \mathrm{~cm} \mathrm{x}$ $5 \mathrm{~cm}$ leading to 200 cells, and all boundaries were defined as open. In both cases after Lima [74], a constant rainfall of $2.25 \mathrm{~mm} / \mathrm{min}(135 \mathrm{~mm} / \mathrm{h})$ was imposed for 15 minutes and the total simulation time was set to 17 minutes. The initial conditions for water depths and flow velocities were set to zero. The initial soil water content was 0.0107 for the loam from Limburg (Test 2), and 0.006 for the clay loam from Alentejo (Test 3), and were not varied during the simulations. In Test 2, Manning 's friction coefficient $\mathrm{n}$ was varied between $0.010-0.033 \mathrm{sm}^{-1 / 3}$, representing the range from bare sand to bare clay loam after Engman [79], as there is no value given for loam. In Test 3, Manning 's friction coefficient was varied between $0.012-0.033 \mathrm{sm}^{-1 / 3}$ corresponding to the range for bare clay loam after Engman [79].

\subsubsection{Test Case 4 - Field Experiment in Thiés Catchment, Senegal [75]}

The domain was discretized in rectangular cells of $10 \mathrm{~cm} \mathrm{x}$ $10 \mathrm{~cm}$ leading to 4141 cells. The upstream boundary was set as open, all other boundaries were set as closed according to Simons [59]. The experimental results in terms of measured rainfall and runoff time series of an 86 minutes long experiment, where the average rainfall intensity was $70.76 \mathrm{~mm} / \mathrm{h}$ (see Fig. 14 in Sect. 3.5), were used for the numerical investigations. The initial conditions for water depths and flow velocities were set to zero. The initial soil water content was varied between zero as calibrated in Simons [59] and 0.2. Manning 's friction law with depth-dependent Manning 's coefficient (Eq. 4 was used with the calibrated parameters from Simons [59]: $n_{0}=0.014 \mathrm{sm}^{-1 / 3}, h_{0}=0.0045 \mathrm{~m}$ and $\varepsilon=0.1$.

\subsubsection{Case Study - Flash Flood Simulations in El Gouna, Egypt}

The model domain of about $11 \mathrm{~km} \mathrm{x} 8 \mathrm{~km}$ was discretized into 438372 rectangular cells of $15 \mathrm{~m} \mathrm{x} 15 \mathrm{~m}$. The topography is represented by the digital surface model (DSM) ALOSWORLD 3D (AW3D30) with a horizontal resolution of $30 \mathrm{~m}$ [80], which was interpolated to a cell size of 10 $\mathrm{m}$. Buildings were incorporated into the DSM by increasing the elevations inside building polygons extracted from OpenStreetMap (see Fig. 3 in Sect. 2.6.4). All boundaries were considered to have a free outflow except for $30 \mathrm{~m}$ at the western boundary, where the inflow from the upstream wadi 
catchment enters the coastal plain. The hydrograph from a hydrological model, which was calibrated with the measured hydrograph by Hadidi [78], was implemented as boundary condition to simulate the flash flood event from 09 March 2014 [81]. Furthermore, a time series of rainfall intensities (Fig. 4) that has been measured at the weather station located at the TU Berlin Campus El Gouna, was imposed as source term in each cell. The accumulated rainfall amount was 34 $\mathrm{mm}$. The initial conditions for water depths and flow velocities were set to zero. The initial soil water content was set to $0.03 \mathrm{~m}^{3} / \mathrm{m}^{3}$ and not varied during the simulation, assuming very dry conditions, which represents the typical conditions in the study area. The friction was varied between 0.01 and $0.02 \mathrm{sm}^{-1 / 3}$ according to the average values for bare sand and bare clay loam after Engman [79].

As most parts of the model domain consist of natural surfaces, mainly in terms of non-vegetated bare sand, infiltration cannot be neglected. After the Harmonized World Soil Database [82] as well as from field investigations, which were carried out within a student research project at TU Berlin Campus El Gouna, the dominant soil type in that area is sand (Fig. 5). Although no measurements are available for model calibration, former studies showed that taking into account the average Green-Ampt parameters for sand after Rawls et al. [1] leads to a strong overestimation of infiltration, as the entire rainfall inside the domain and almost the whole incoming flood wave from the large wadi catchment completely infiltrated before reaching the city of El Gouna [11]. As there have been large flooding areas observed by the population-reported in personal conversations with shop owners and staff members of the desalination plant as well as through photographs of inundated areas and resulting

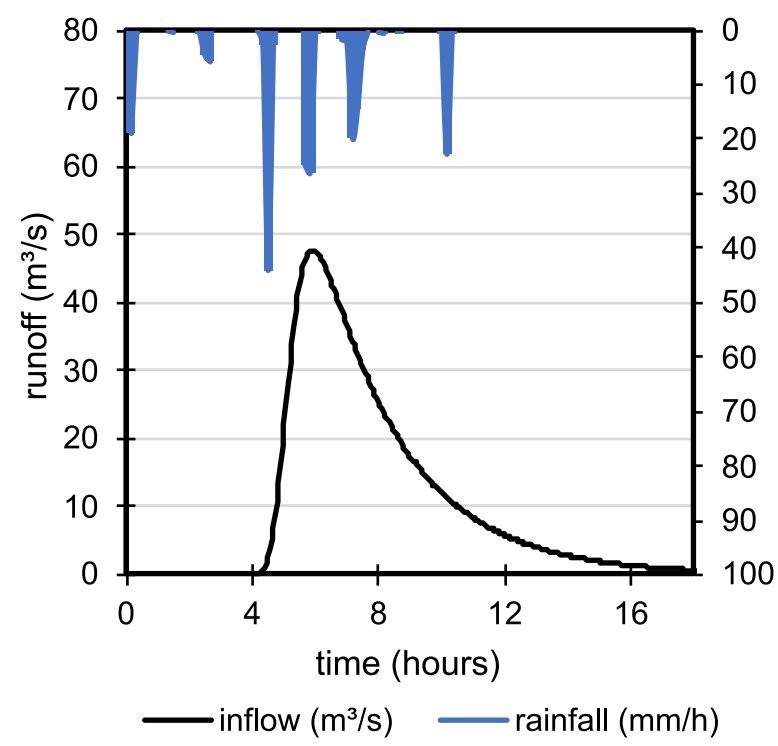

Fig. 4 Rainfall and inflow imposed as source and boundary condition in the model, respectively

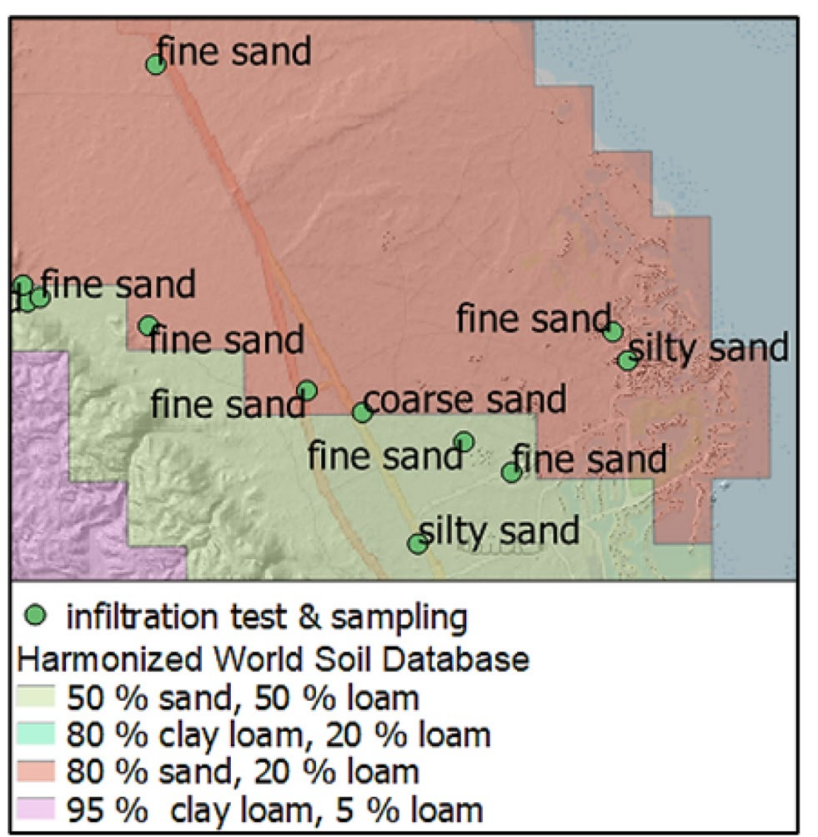

Fig. 5 Soil texture classes according to the Harmonized World Soil Database and determined from double-ring infiltrometer tests (map: (C)OpenStreetMap contributors)

damages-it is obvious, that the infiltration is not represented realistically. In addition to the overestimation of infiltration due to the assumed Green-Ampt parameters, also spatial rainfall patterns, which are not taken into account as the rainfall data of only one weather station was available, could also contribute to this wrong representation. In particular, bare soils in arid areas are lacking vegetation cover and have therefore no protection from raindrop impact, which might lead to soil crusting coming along with a large reduction of the infiltration capacity [49]. Therefore, the approach of a Green-Ampt model for crusted soils as described in Eq. 9 is taken into account, and the impact of a crust as well as friction is studied. As for sand and loamy sand, almost all water infiltrated very fast, loam was also considered, as this texture class is also occurring in this area according to the Harmonized World Soil Database.

\section{Results}

\subsection{Sensitivity Analysis}

For the test case of the Thiès catchment, a sensitivity analysis of the Green-Ampt parameters, different crust parameters for the two approaches presented in Eqs. 9 and Eq. 10, as well as the parameters of the depth-dependent Manning approach as given in Eq. 4 is presented in the following. Table 6 shows the parameter values for the reference case, which is represented with a solid black line in Figs. 6, 7, 8, 
Fig. 6 Variation of Green-Ampt parameters: hydraulic conductivity $(\mathrm{K})$, capillary suction at wetted front $\left(h_{\mathrm{f}}\right)$, saturated soil water content $\left(\theta_{\mathrm{s}}\right)$, and initial soil water content $\left(\theta_{\mathrm{i}}\right)$
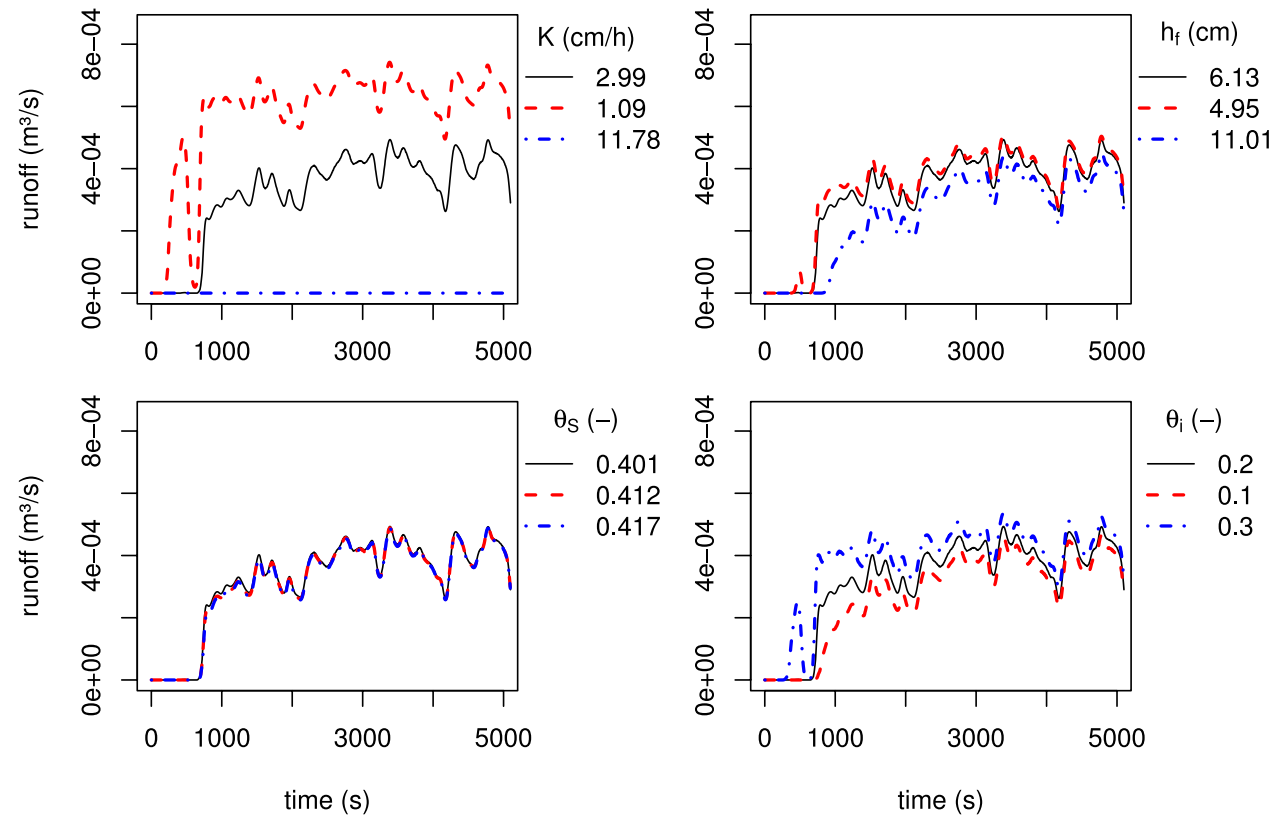

as well as for the basic crust setting, when the different crust parameters are varied.

The Green-Ampt parameters for the reference case correspond to the ones after Rawls et al. [1] for loamy sand and are varied sequentially with the values for sand and sandy loam. From Fig. 6, it becomes obvious that the hydraulic conductivity of the three consecutive soil types has the strongest influence on the hydrograph, the capillary suction head and the initial soil water content also have significant influence especially at the beginning, while the saturated soil water content is neglectable in the presented cases. It has to be mentioned that this parameter also has the lowest variation between the three selected consecutive soil types. As expected, the infiltration is higher with increasing hydraulic conductivity as well as with increasing capillary suction leading to decreased surface runoff, while a higher initial soil water content leads to less infiltration and a higher surface runoff. Figure 7 shows the results of varying the crust parameters $\mathrm{K}_{\mathrm{c}}$ and $\mathrm{Z}_{\mathrm{c}}$ after Eq. 9, as well as SC and $\Psi_{\mathrm{i}}$ after Eq. 10. For the approach after Eq. 9, the hydraulic conductivity of the crust was varied between values for loam, sandy clay loam, and clay loam, while the crust thickness was varied between 2, 5 and $10 \mathrm{~mm}$. For the the approach after Eq. 10, the values of the reduction factor
Fig. 7 Variaton of different crust parameters: hydraulic conductivity of the crust $\left(\mathrm{K}_{\mathrm{c}}\right)$, depth of the crust $\left(\mathrm{Z}_{\mathrm{c}}\right)$, reduction factor of subcrust conductivity (SC), and steady-state matric potential drop at crust/subcrust interface $\left(\Psi_{\mathrm{i}}\right)$
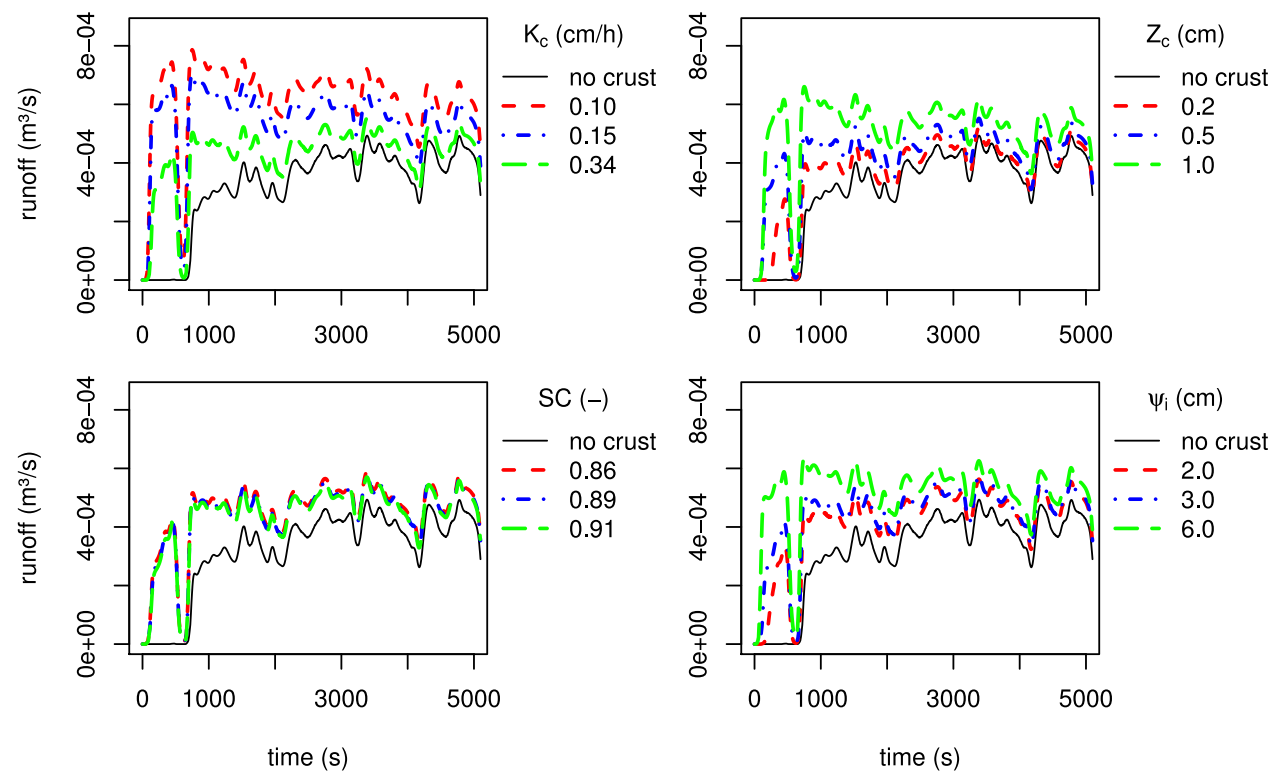
Fig. 8 Variation of the subcrust hydraulic conductivity $\left(K_{S C}\right)$ for the approach with $\mathrm{SC}$ and $\Psi_{\mathrm{i}}$ for loamy sand, and the parameters of the depth-dependent Manning law: minimum Manning coefficient $\left(n_{0}\right)$, depth beyond which $\mathrm{n}$ is assumed to be constant $\left(h_{0}\right)$, and the parameter accounting for drag $(\varepsilon)$
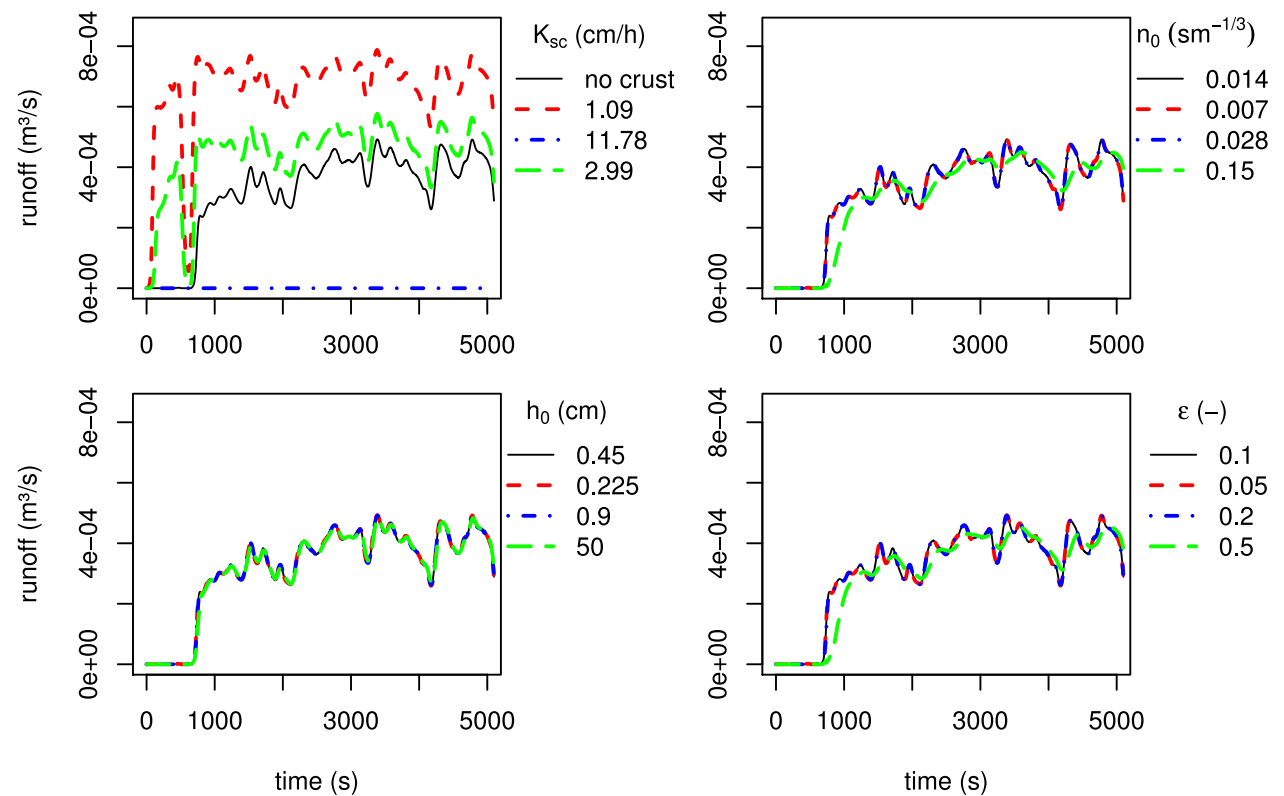

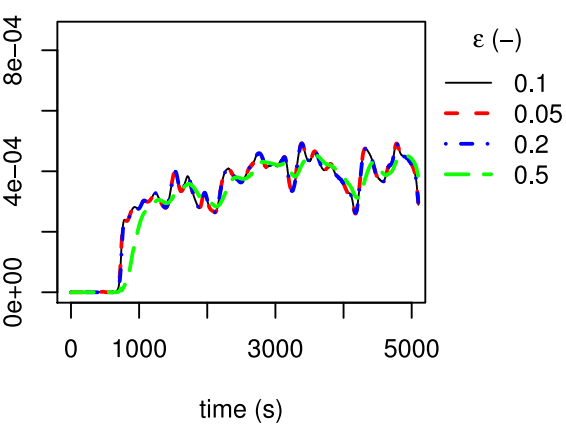

for the subcrust conductivity and the steady-state matric potential drop at the crust/subcrust interface were varied corresponding to the values for sandy loam, loamy sand, and sand after Rawls et al. [56]. As expected, both crust approaches significantly reduce the infiltration and therefore lead to higher surface runoff. Lowering the hydraulic conductivity of the crust $\mathrm{K}_{\mathrm{c}}$ or increasing the depth of the crust $Z_{c}$ lead to increased runoff. Changing SC between the selected soil types has almost no influence on the hydrograph, while increasing $\Psi_{\mathrm{i}}$ significantly increases surface runoff and therefore decreases the infiltration.

The upper left diagram in Fig. 8 shows the effect, when the crust consideration after Eq. 10 is used with values for loamy sand and the subcrust conductivity is varied. Here, it becomes obvious that the subcrust conductivity has still a very strong effect on the infiltration and surface runoff, when using this approach for the crust, as for sand (11.78 $\mathrm{cm} / \mathrm{h}$ ) the crust effect is not visible at all as the water directly infiltrates, and for sandy loam $(1.09 \mathrm{~cm} / \mathrm{h})$ the surface runoff is much higher. The three graphs for the parameters of

Table 6 Parameter values for the reference case and basic case when a crust is considered either after Eqs. 9 or 10

\begin{tabular}{|c|c|c|c|}
\hline \multicolumn{4}{|c|}{ Green-Ampt parameters } \\
\hline $\mathrm{K}(\mathrm{cm} / \mathrm{h})$ & $h_{\mathrm{f}}(\mathrm{cm})$ & $\theta_{\mathrm{i}}\left(\left(\mathrm{m}^{3} / \mathrm{m}^{3}\right)\right.$ & $\theta_{\mathrm{s}}\left(\mathrm{m}^{3} / \mathrm{m}^{3}\right)$ \\
\hline 2.99 & 6.13 & 0.2 & 0.401 \\
\hline \multicolumn{4}{|c|}{ Crust parameters for different approaches } \\
\hline $\mathrm{K}_{\mathrm{c}}(\mathrm{cm} / \mathrm{h})$ & $\mathrm{Z}_{\mathrm{c}}(\mathrm{cm})$ & $\mathrm{SC}(-)$ & $\Psi_{\mathrm{i}}(\mathrm{cm})$ \\
\hline 0.34 & 0.5 & 0.89 & 0.03 \\
\hline \multicolumn{4}{|c|}{ Friction parameters } \\
\hline$n_{0}\left(\mathrm{sm}^{-1 / 3}\right)$ & $h_{0}(\mathrm{~cm})$ & $\varepsilon(-)$ & - \\
\hline 0.014 & 0.0045 & 0.1 & - \\
\hline
\end{tabular}

the depth-dependent friction law show, that all parameters have almost no influence on the hydrograph when taking the double or half of the values. Only, when setting the minimum Manning coefficient $n_{0}$ to much higher values than the range for sand after Engman [79] $\left(0.010-0.016 \mathrm{sm}^{-1 / 3}\right)$, as for example here to $0.15 \mathrm{sm}^{-1 / 3}$ corresponding to the recommended value for short grass prairie, an influence can be observed. It has to be mentioned, that in larger systems as for example the model area of El Gouna, the friction has a significant influence on the infiltration, as shown later in Sect. 3.6.

\subsection{Test Case 1 - Laboratory Experiment after Smith and Woolhiser [61]}

The simulated runoff hydrographs for the different parameter sets (as described in Sect. 2.7) are shown in Fig. 9, and the corresponding parameter sets as well as indicators for the goodness-of-fit are summarized in Table 7. When the average Green-Ampt parameters after Rawls et al. [1] for sand are considered in the model, the surface runoff is strongly overestimated for the whole rising limb of the hydrograph, and runoff starts about 180 seconds before the observed runoff. However, the peak discharge is well captured in magnitude and occurs only 9 seconds earlier than the observed one. The NSE for the overall hydrograph is -0.245 , indicating a bad agreement between simulated and observed hydrograph (see Table 5, line 1; green line with circles in Fig. 9. When using the Green-Ampt parameters that resulted from the automatic calibration for the ranges of effective porosity and capillary suction head at the wetted front for sand and the hydraulic conductivity as given in Rawls et al. [1], the runoff is only slightly overestimated at the first part of the rising limb and 
Fig. 9 Different simulated runoff hydrographs for for the laboratory experiment after Smith and Woolhiser [61]

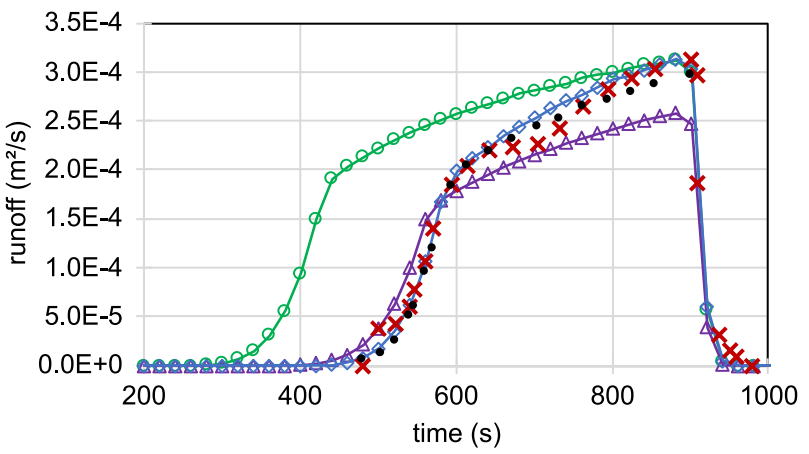

$\times$ observed after Smith \& Woolhiser [64]

- Delfs et al. [10] simulated

_ - average values for sand after Rawls et al. [54]

$\triangle$ optimized, range for sand after Rawls et al. [54]

$\diamond$ optimized, range for loamy sand- sand after Rawls et al. [54]

Table 7 Different sets of Green-Ampt parameters for simulations of the rainfall-runoff experiment after Smith and Woolhiser [61]

\begin{tabular}{|c|c|c|c|c|c|c|c|}
\hline & \multirow{2}{*}{$\begin{array}{l}\text { Initial soil water } \\
\text { content } \\
\theta_{\mathrm{i}} \\
\left(\mathrm{m}^{3} / \mathrm{m}^{3}\right)\end{array}$} & \multicolumn{3}{|c|}{ Green Ampt parameters } & \multirow{2}{*}{$\begin{array}{l}\text { Friction } \\
C_{\text {lam }} \\
\left(\mathrm{m}^{-1} \mathrm{~s}^{-1}\right)\end{array}$} & \multicolumn{2}{|c|}{ Performance } \\
\hline & & $\begin{array}{l}\theta_{\mathrm{s}} \\
\left(\mathrm{m}^{3} / \mathrm{m}^{3}\right)\end{array}$ & $\begin{array}{l}\mathrm{K} \\
(\mathrm{cm} / \mathrm{h})\end{array}$ & $\begin{array}{l}h_{\mathrm{f}} \\
(\mathrm{cm})\end{array}$ & & $\begin{array}{l}\text { NSE } \\
-\end{array}$ & $\begin{array}{l}K G E_{\mathrm{np}} \\
-\end{array}$ \\
\hline average values sand* & 0.083 & 0.417 & 11.78 & 4.95 & 133333 & -0.245 & 0.553 \\
\hline optimized, range sand ${ }^{*}$ & 0.080 & 0.397 & 11.78 & 7.8 & 133333 & 0.871 & 0.919 \\
\hline optimized, range loamy sand - sand ${ }^{*}{ }^{* *}$ & 0.123 & 0.425 & 7.56 & 18.9 & 1328383 & 0.984 & 0.966 \\
\hline Delfs et al. [62] (different model) & 0.084 & 0.399 & 10.20 & - & 133333 & 0.981 & 0.951 \\
\hline
\end{tabular}

*after Rawls et al. [1]

*** and calibration of $\theta_{\mathrm{i}}$ and $C_{\mathrm{lam}}$ (see Table 8

the runoff starts 80 seconds later than in the observations. But between the times of 580 and 921 seconds, the simulated hydrograph underestimated the observed one, leading to a peak discharge which is only $82 \%$ of the observed one (see Table 7, line 2; purple line with triangles in Fig. 9). With a NSE of 0.871 , the overall agreement with the observed hydrograph is much better than with the average parameters for sand. Finally, optimization was carried out, where all Green-Ampt parameters (effective porosity, hydraulic conductivity, and capillary suction head) were varied in larger ranges, where the minimum and maximum values of the ranges from sand and loamy sand after Rawls et al. [1] were taken into account. Furthermore, also the initial soil water content as well as the friction coefficient were varied within the ranges given in Table 8 . The starting time of surface runoff as well as the peak discharge magnitude and time, and the overall shape of the observed hydrograph could be captured very well (see Table 7, line 3; blue line with diamonds in Fig. 9. With a NSE of 0.986 the performance is very good and comparable to the results, which were reported in Delfs et al. [62] (using a diffusive wave model for overland flow, Richards model for fluid movement in the unsaturated soil, and an interface layer concept for coupling) showing a NSE of 0.982 (see Table 7, line 4; black dots in Fig. 9. All simulations could not capture the slightly slower decrease in discharge towards the end of the recession limb, which was also reported in the simulation discussion in Smith and Woolhiser
[61]. When using values for sand after Innovyze [2] surface runoff was even more overestimated, and the resulting NSE of -33.395 reflects the bad performance. Therefore, the values after Innovyze [2] were not further taken into account in Fig. 9 and Table 7. In Fig. 10 the infiltration rates for the different parameter sets are shown, and as there are no observed infiltration rates available, compared to the ones simulated from Delfs et al. [62] (black dots in Fig. 10). Again, the underestimation of infiltration when considering average Green-Ampt parameters for sand after Rawls et al. [1] is visible in the lower infiltration rates (green line with circles in Fig. 10). The infiltration rate with optimized parameters for the ranges of sand (purple line with triangles in Fig. 10) agrees well with the one simulated by Delfs et al. [62] until the time of 480 seconds and overestimates it afterward. With optimized parameters for the larger ranges between loamy sand and sand, it is the other way round (blue line with diamonds in Fig. 10).

Table 8 Parameter ranges for the optimization routine to calibrate the Green-Ampt parameters between loamy sand-sand and the friction coefficient for laminar flow $C_{\text {lam }}$

\begin{tabular}{|c|c|c|c|c|c|}
\hline & $\begin{array}{l}\theta_{\mathrm{i}} \\
\left(\mathrm{m}^{3} / \mathrm{m}^{3}\right)\end{array}$ & $\begin{array}{l}\theta_{\mathrm{s}} \\
\left(\mathrm{cm}^{3} / \mathrm{cm}^{3}\right)\end{array}$ & $\begin{array}{l}\mathrm{K} \\
(\mathrm{cm} / \mathrm{h})\end{array}$ & $\begin{array}{l}h_{\mathrm{f}} \\
(\mathrm{cm})\end{array}$ & $\begin{array}{l}C_{\mathrm{lam}} \\
\left(\mathrm{cm}^{-1} \mathrm{~h}^{-1}\right)\end{array}$ \\
\hline Min & 0.000 & 0.329 & 2.99 & 0.97 & $4.68 \cdot 10^{7}$ \\
\hline Max & 0.126 & 0.480 & 11.78 & 27.94 & $5.04 \cdot 10^{7}$ \\
\hline
\end{tabular}


Fig. 10 Infiltration rates over time for different simulations of the experiment after Smith and Woolhiser [61]

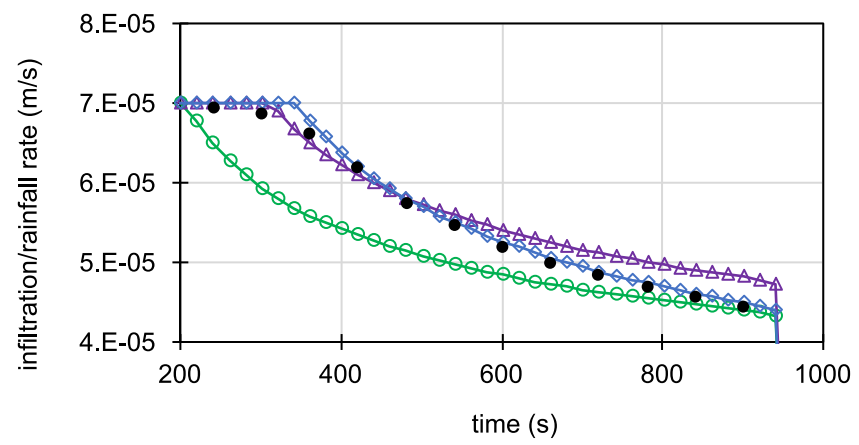

- Delfs et al. [10] simulated

- - average values for sand after Rawls et al. [54]

$\triangle$ optimized, range for sand after Rawls et al. [54]

$\diamond$ optimized, range for loamy sand - sand after Rawls et al. [54]

\subsection{Test Case 2 - Laboratory Experiment for Loam (Limburg) after Lima [74]}

Figure 11 shows the hydrographs for the loam soil of Limburg when considering different Green-Ampt parameters compared to the observed one. The corresponding parameter sets as well as indicators for the goodness-of-fit are given in Table 9. Similar to the test case of the Smith and Woolhiser experiment (Sect. 2.6.1), surface runoff is strongly overestimated when considering the average Green-Ampt parameters for loam after Rawls et al. [1] and starts about 180 seconds earlier than the observed one. The peak discharge is about $17 \%$ higher than the observed one, and the NSE for the overall hydrograph is -1.186 , and the $K G E_{\text {np }}$ is 0.2 indicating both a bad agreement to the observations (see Table 9, line 1; green line with circles in Fig. 8). The Manning coefficient was set to $0.020 \mathrm{sm}_{-1 / 3}$, which is the recommended value for bare clay loam after Engman [79]. The result when using the optimized parameters within the ranges for loam after Rawls et al. [1] agrees well with the measurements. The start time of surface runoff as well as the overall hydrograph shape are well captured, but the peak discharge is underestimated and only $86 \%$ of the observed one. The NSE is 0.928 and the $K G E_{\mathrm{np}}$ is 0.924 (see Table 9, line 2; purple line with triangles in Fig. 11). Almost the same hydrograph with an NSE of 0.930 and $K G E_{\text {np }}$ of 0.927 was simulated when using the measured and estimated values of saturated soil water content and the hydraulic conductivity after Lima [74], and calibrating only the capillary suction head hf and Manning 's friction coefficient (see Table 9, line 3; blue line with diamonds in Fig. 11). For both cases, Manning 's friction coefficient was calibrated within the range of $0.010-0.033 \mathrm{sm}^{-1 / 3}$, representing the range from bare sand to bare clay loam after Engman [79], and resulting value was $0.021 \mathrm{sm}_{-1 / 3}$ in both cases, and therefore very close to the recommended value of $0.020 \mathrm{sm}^{-1 / 3}$ for clay loam after Engman [79]. The capillary suction head was calibrated within the range for loam after Rawls et al. [1]. The fact that two parameter sets with significantly different values for hydraulic conductivity and capillary suction head generated almost the same hydrographs, emphasizes the problem of equifinality during the calibration process of several calibration parameters that depend on each other. A higher hydraulic conductivity can be sort of "compensated" by a lower capillary suction head, although the different processes of capillary-driven and gravity-driven infiltration are dominating at different states of soil water content and therefore different times of the rainfall event. Taking into account the average values for loam after Innovyze [2] with the mean value for the hydraulic conductivity after Akan [67], lead to better results than with average values after Rawls et al. [1] (see Table 9, line 4; orange line with plus signs in Fig. 11). But with a NSE of 0.045 the results are still much worse than the results with calibrated parameters, where the NSE is 0.928 .
Fig. 11 Runoff hydrographs for different simulations of the experiment for loamy soil after Lima [74]
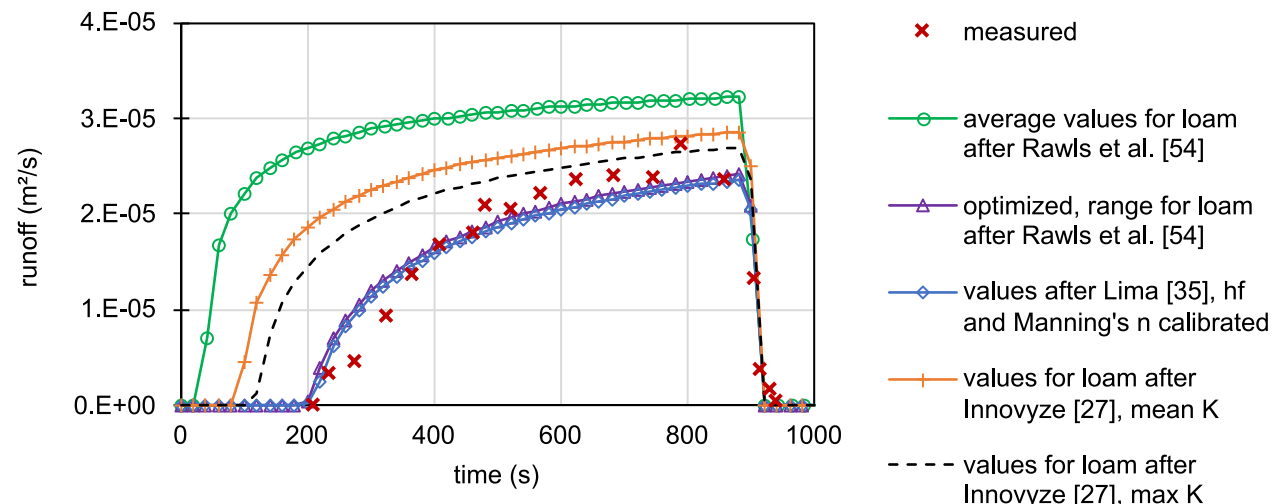
Table 9 Different sets of Green-Ampt parameters for simulations of the rainfall-runoff experiment on loamy soil after Lima [74]

\begin{tabular}{|c|c|c|c|c|c|c|c|}
\hline & \multirow{2}{*}{$\begin{array}{l}\text { Initial soil } \\
\text { water content } \\
\theta_{\mathrm{i}} \\
\left(\mathrm{m}^{3} / \mathrm{m}^{3}\right)\end{array}$} & \multicolumn{3}{|c|}{ Green Ampt parameters } & \multirow{2}{*}{$\begin{array}{l}\text { Friction } \\
\text { Manning } \\
\left(\mathrm{sm}^{-1 / 3}\right)\end{array}$} & \multicolumn{2}{|c|}{ Performance } \\
\hline & & $\begin{array}{l}\theta_{\mathrm{s}} \\
\left(\mathrm{m}^{3} / \mathrm{m}^{3}\right)\end{array}$ & $\begin{array}{l}\mathrm{K} \\
(\mathrm{cm} / \mathrm{h})\end{array}$ & $\begin{array}{l}h_{\mathrm{f}} \\
(\mathrm{cm})\end{array}$ & & $\begin{array}{l}\text { NSE } \\
-\end{array}$ & $\begin{array}{l}K G E_{\mathrm{np}} \\
-\end{array}$ \\
\hline average values loam after Rawls et al. [1] & 0.0107 & 0.434 & 0.34 & 8.90 & 0.020 & -1.186 & 0.200 \\
\hline optimized, range loam after Rawls et al. [1] & 0.0107 & 0.503 & 0.34 & 53.90 & 0.021 & 0.928 & 0.924 \\
\hline values after Lima [74], $h_{\mathrm{f}}$ and Manning's n calibrated & 0.0107 & 0.506 & 0.60 & 30.40 & 0.021 & 0.930 & 0.927 \\
\hline values for loam after Innovyze [2], mean $\mathrm{K}$ & 0 & 0.310 & 0.57 & 20.32 & 0.020 & 0.045 & 0.496 \\
\hline values for loam after Innovyze [2], max $\mathrm{K}$ & 0 & 0.310 & 0.76 & 20.32 & 0.020 & 0.429 & 0.630 \\
\hline
\end{tabular}

When taking instead of the mean the maximum value for the hydraulic conductivity after Akan [67], the results improved but still strongly underestimate infiltration leading to a NSE of 0.429 (see Table 9, line 5; black dashed line Fig. 11).

Figure 12 presents the infiltration rates, and it clearly shows, that in the case of average values for loam (green line with circles in Fig. 12), the infiltration rate shortly reaches the maximum value of rainfall intensity, but directly starts to drop after the first time step. For the two cases with calibrated parameters the infiltration rates just start to decrease after 180 seconds and decrease much slower (purple line with triangles and blue line with diamonds in Fig. 12). When considering the values for loam after Innovyze [2] with the mean value for the hydraulic conductivity, the infiltration rate starts to decrease after 80 seconds (orange line with plus signs in Fig. 12), and after 120 seconds if the maximum value for the hydraulic conductivity was taken (black dashed line in Fig. 12). As the infiltration rate was not directly measured, the difference between rainfall and observed runoff was taken as reference.

\subsection{Test Case 3 - Laboratory Experiment for Clay Loam (Alentejo) after Lima [74]}

Figure 10 shows the hydrographs for the clay loam soil of Alentejo, and the corresponding parameter sets as well as indicators for the goodness-of-fit are given in Table 8. When having in mind the two other test cases presented before, it is remarkable that in this case the simulated hydrograph agrees well with the observed one when considering the average values for clay loam after Rawls et al. [1]. The surface runoff is only slightly overestimated and starts about 60 seconds earlier than the observed one. The NSE of 0.724 and of 0.808 indicate a relatively good agreement as well (see Table 10, line 1; green line with circles in Fig. 13). The Manning coefficient was set to $0.020 \mathrm{sm}^{-1 / 3}$ corresponding to the recommended value for bare clay loam after Engman [79]. Another simulation was done considering the values from optimization when taking into account the ranges for clay loam for the effective porosity and the capillary suction head and the average value of hydraulic conductivity after Rawls et al. [1], and for the Manning coefficient a range between 0.012 and $0.033 \mathrm{sm}^{-1 / 3}$ corresponding to the range for bare clay loam after Engman [79]. Surface runoff starts approximately 20 seconds before the observed one, leading to a slight overestimation of runoff at the beginning. After about 100 seconds until the end, the simulated hydrograph slightly underestimates the observed one. The NSE of 0.924 and of 0.862 are a little bit higher than for the average values for clay loam (see Table 10, line 2; purple line with triangles in Fig. 13). When taking the measured and estimated values
Fig. 12 Infiltration rates over time for different simulations of the experiment for loamy soil after Lima [74]

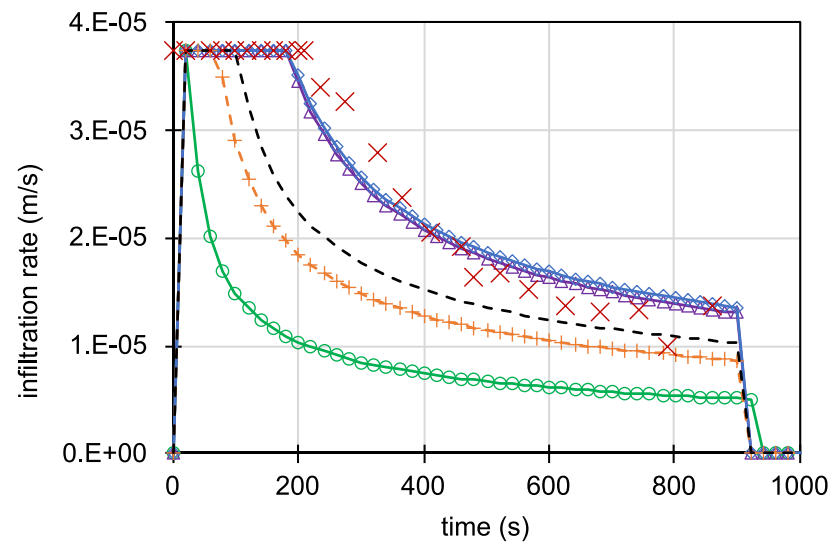


Fig. 13 Runoff hydrographs for different simulations of the experiment after Lima for clay loam [74]

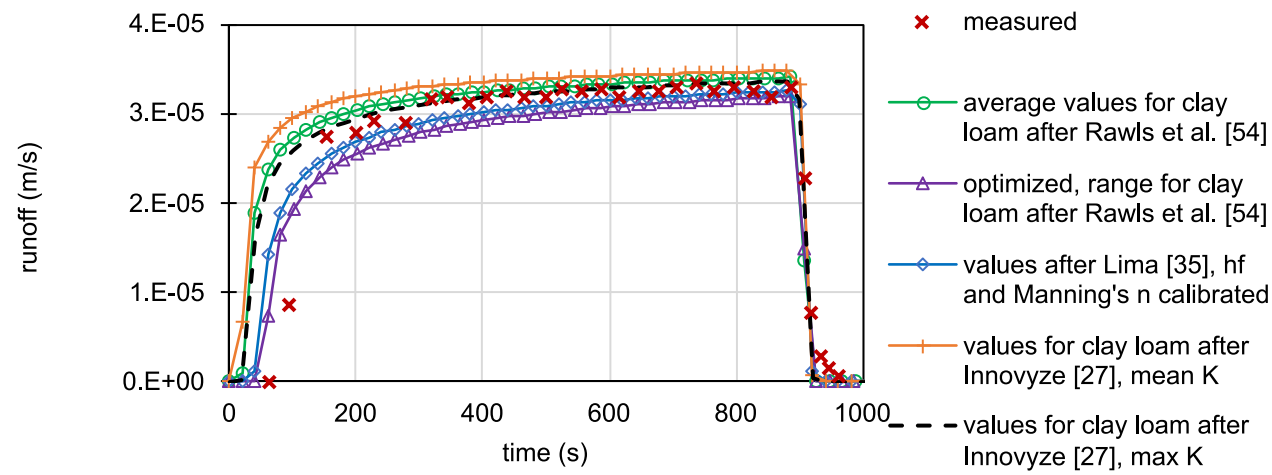

for the saturated soil water content and the hydraulic conductivity after Lima [74] and calibrating only the Manning's coefficient and capillary suction head, the results show a very similar hydrograph, but surface runoff starts about 40 seconds before the measured one, first slightly overestimates the measured runoff and after about 120 seconds underestimates it. The NSE of 0.888 is slightly below the one for the optimized parameters, while the is slightly higher (see Table 10, line 3; blue line with diamonds in Fig. 13). For these two cases, where also Manning 's coefficient was calibrated, values of 0.033 and $0.032 \mathrm{sm}^{-1 / 3}$, respectively, were obtained being at the upper bound of the range for bare clay loam after Engman [79]. Taking into account the average values for clay loam after Innovyze, the results are slightly worse than with average values after Rawls et al. [1] when taking the mean value for the hydraulic conductivity after Akan [67] (see Table 10, line 4; orange line with plus signs in Fig. 13), and slightly better when taking into account the maximum value for the hydraulic conductivity after Akan [67] (see Table 10, line 5; black dashed line in Fig. 13). Manning's coefficient was not calibrated here but fixed to be $0.020 \mathrm{sm}^{-1 / 3}$ representing the recommended value for bare clay loam to simulate the case that there is no runoff data available for calibration. If Manning's coefficient was calibrated also here, it resulted also in a value of $0.033 \mathrm{sm}^{-1 / 3}$, but the impact on the hydrograph was minor.

\subsection{Test case 4-Field experiment in Thiès catchment, Senegal [75]}

The simulated hydrographs of different parameter sets are compared to the measured data in Fig. 14, the different parameter sets as well as goodness-of-fit indicators are given in Table 11. If the average values for sand after Rawls et al. [1] are considered, infiltration is completely overestimated as no surface runoff occurs, which leads to an NSE of -5.05 (see Table 11, line 1; green dotted line in Fig. 14). When considering instead the average values for loamy sand, the simulated hydrograph agrees much better with the observed one, but still underestimates it most of the time. The overall NSE is 0.520 and the KGEnp is 0.656 (see Table 11, line 2; orange dashed line in Fig. 14). When taking instead the values for sand after Innovyze with the mean value for the hydraulic conductivity after Akan [67] into account, the second one of the two smaller peaks in the beginning of the observed hydrograph is relatively well captured, while the rest of the hydrograph is strongly overestimated (see Table 11, line 3; purple plus signs in Fig. 14). The overall NSE is 0.417 indicating a much better fit than with the average values for sand after Rawls et al. [1]. The KGEnp of 0.660 gives a better agreement than with the average values for loamy sand after Rawls et al. [1]. Considering the values after Innovyze with the

Table 10 Different sets of Green-Ampt parameters for simulations of the rainfall-runoff experiment on clay loam after Lima [74]

\begin{tabular}{|c|c|c|c|c|c|c|c|}
\hline & \multirow{2}{*}{$\begin{array}{l}\text { Initial soil } \\
\text { watercontent } \\
\theta_{\mathrm{i}} \\
\left(\mathrm{m}^{3} / \mathrm{m}^{3}\right)\end{array}$} & \multicolumn{3}{|c|}{ Green Ampt parameters } & \multirow{2}{*}{$\begin{array}{l}\text { Friction } \\
\text { Manning } \\
\left(\mathrm{sm}^{-1 / 3}\right)\end{array}$} & \multicolumn{2}{|c|}{ Performance } \\
\hline & & $\begin{array}{l}\theta_{\mathrm{s}} \\
\left(\mathrm{m}^{3} / \mathrm{m}^{3}\right)\end{array}$ & $\begin{array}{l}\mathrm{K} \\
(\mathrm{cm} / \mathrm{h})\end{array}$ & $\begin{array}{l}h_{\mathrm{f}} \\
(\mathrm{cm})\end{array}$ & & $\begin{array}{l}\text { NSE } \\
-\end{array}$ & $\begin{array}{l}K G E_{\mathrm{np}} \\
\text { - }\end{array}$ \\
\hline average values clay loam after Rawls et al. [1] & 0.006 & 0.309 & 0.10 & 20.88 & 0.020 & 0.724 & 0.808 \\
\hline optimized, range clay loam after Rawls et al. [1] & 0.006 & 0.390 & 0.10 & 47.90 & 0.033 & 0.924 & 0.862 \\
\hline values after Lima [74], $h_{\mathrm{f}}$ and Manning's n calibrated & 0.0107 & 0.506 & 0.60 & 30.40 & 0.021 & 0.930 & 0.927 \\
\hline values for loam after Innovyze [2], mean $\mathrm{K}$ & 0 & 0.240 & 0.07 & 25.40 & 0.020 & 0.668 & 0.823 \\
\hline values for loam after Innovyze [2], $\max \mathrm{K}$ & 0 & 0.240 & 0.13 & 25.40 & 0.020 & 0.801 & 0.857 \\
\hline
\end{tabular}


Fig. 14 Runoff hydrographs for different simulations of the rainfall-runoff experiment in the Thiès catchment in Senegal

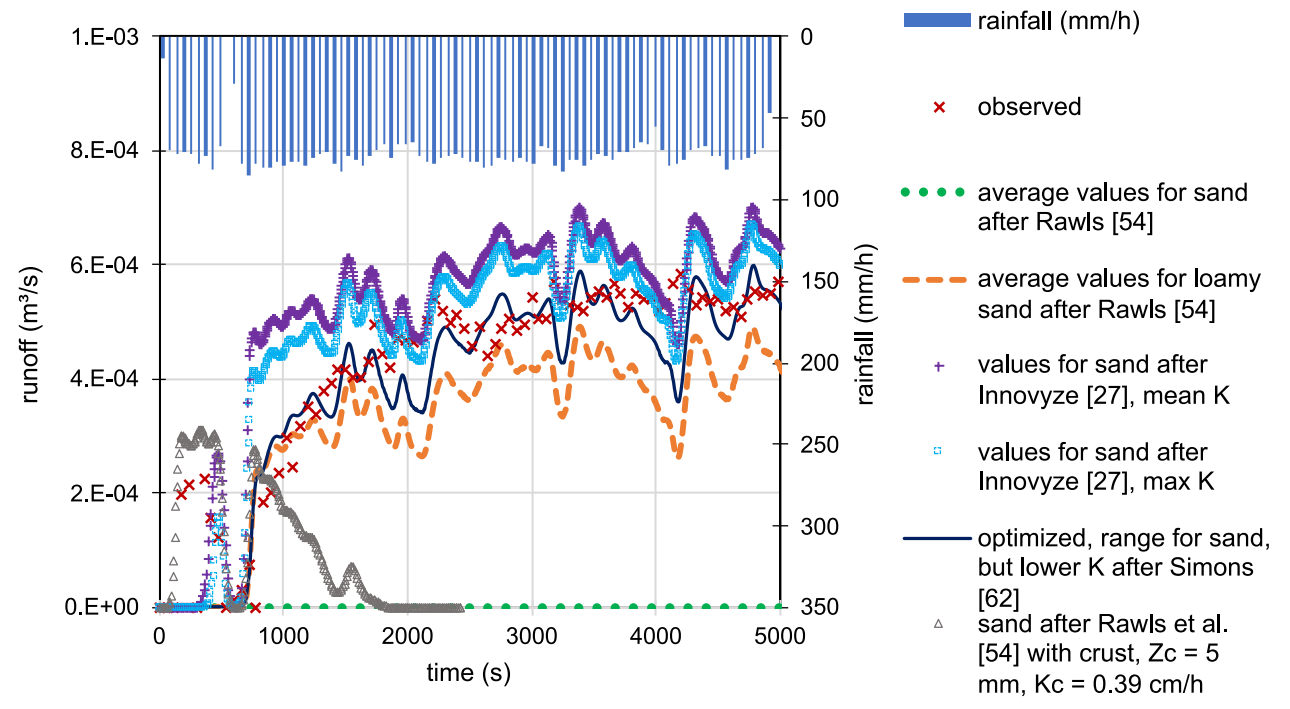

maximum value for the hydraulic conductivity after Akan [67] results in an improved hydrograph with a NSE of 0.628 and a KGEnp of 0.731 , but still clearly underestimates infiltration (see Table 11, line 4; light blue rectangles in Fig. 14). The optimization was carried out for the range of sand after Rawls et al. [1], however a decreased lower threshold according to the calibrated value in Simons [59] was used for the hydraulic conductivity. The hydrograph resulting from the optimized parameters does not capture the measured two smaller peaks in the beginning of the observed runoff, but later on it fits the observations relatively well, leading to an overall NSE of 0.810 (see Table 11, line 5; dark blue solid line in Fig. 14). A last simulation was done considering the modified Green-Ampt model with an effective hydraulic conductivity of crust and subcrust soil as given in Eq. 9 in Sect. 2.2. To exemplarily see the effect of this modification accounting for a surface crust, one simulation with the average values for sand after Rawls et al. [1] for the subcrust soil, and a crust of $5 \mathrm{~mm}$ thickness and with an hydraulic conductivity of $0.39 \mathrm{~cm} / \mathrm{s}$, which is 30 times lower than the one for the subcrust soil (11.78 cm/s), was carried out. The simulated hydrograph considering such crust captures very well the beginning of surface flow in terms of the first smaller peaks, although it overestimates these peaks by about $35 \%$. After about 800 seconds, the simulated hydrograph starts to continuously decrease and reaches zero after about 1900 seconds, while the observed one is continuously increasing. Therefore, the simulated values strongly underestimate the observed ones, which leads to an overall bad performance with a NSE of -4.823 (see Table 11, line 6; grey triangles in Fig. 14). As shown in Eq. 9, the effective hydraulic conductivity equals the crust hydraulic conductivity as long as the wetted depth is smaller than the crust thickness, and is calculated by a thickness-weigthed harmonic mean between the hydraulic conductivities of the crust and subcrust soil, when the wetted depth is larger than the crust thickness. Therefore, with increasing time, the infiltration increases due to a stronger impact of the hydraulic conductivity of the subcrust soil on the effective hydraulic conductivity.

Table 11 Different sets of Green-Ampt parameters for simulations of the rainfall-runoff experiment in the Thì̀s catchment in Senegal

\begin{tabular}{|c|c|c|c|c|c|c|}
\hline & \multirow{2}{*}{$\begin{array}{l}\text { Initial soil water content } \\
\theta_{\mathrm{i}} \\
\left(\mathrm{m}^{3} / \mathrm{m}^{3}\right)\end{array}$} & \multicolumn{3}{|c|}{ Green Ampt parameters } & \multicolumn{2}{|c|}{ Performance } \\
\hline & & $\begin{array}{l}\theta_{\mathrm{s}} \\
\left(\mathrm{m}^{3} / \mathrm{m}^{3}\right)\end{array}$ & $\begin{array}{l}\mathrm{K} \\
(\mathrm{cm} / \mathrm{h})\end{array}$ & $\begin{array}{l}h_{\mathrm{f}} \\
(\mathrm{cm})\end{array}$ & $\begin{array}{l}\text { NSE } \\
-\end{array}$ & $\begin{array}{l}K G E_{\text {np }} \\
-\end{array}$ \\
\hline average values sand after Rawls et al. [1] & 0.200 & 0.417 & 11.78 & 4.95 & -5.052 & -1.125 \\
\hline average values loamy sand after Rawls et al. [1] & 0.20 & 0.401 & 2.99 & 6.13 & 0.520 & 0.656 \\
\hline values for sand after Innovyze [2], mean $K$ & Initial soil moisture deficit & 0.340 & 0.95 & 10.16 & 0.417 & 0.660 \\
\hline values for sand after Innovyze [2], max K & Initial soil moisture deficit & 0.340 & 1.14 & 10.16 & 0.628 & 0.731 \\
\hline $\begin{array}{l}\text { optimized, range sand, but lower } \mathrm{K} \text { from calibra- } \\
\text { tion after Simons [59] }\end{array}$ & 0.200 & 0.378 & 1.62 & 19.20 & 0.810 & 0.788 \\
\hline sand with crust, $Z_{c}: 5 \mathrm{~mm}, K_{c}: 0.39 \mathrm{~cm}$ & 0.200 & 0.417 & 11.78 & 4.95 & -4.823 & -1.064 \\
\hline
\end{tabular}




\subsection{Case Study - Flash Flood Simulations in EI Gouna, Egypt}

Figure 15 shows the water depths in the model domain after 9 hours of simulation time considering infiltration with 1) average values for loam after Rawls et al. [1] and 2) average values for sand after Rawls et al. [1] combined with a surface crust after Eq. 9 of $5 \mathrm{~mm}$ thickness with a hydraulic conductivity for clay after Rawls et al. [1] and a Manning's friction coefficient of $n=0.01 \mathrm{sm}^{-1 / 3}$ according to the average value for bare sand, and $n=0.02 \mathrm{sm}^{-1 / 3}$ according to the average value for bare clay loam after Engman [79], respectively. Comparing the results with infiltration for loam and for sand with a crust of $5 \mathrm{~mm}$, it becomes obvious that for loam the local rainfall inside the model domain almost completely infiltrated, while for sand with a 5-mm-thick crust, flooding areas apart from the main stream coming from Wadi Bili were generated, which better agrees with the observations reported by the community. Strong damages were, for example, reported at construction sites along the shore of one lagoon in the South of El Gouna, where the flow was draining into the lagoon. These inundation areas and the stream draining into the lagoon are captured when considering sand with a crust of $5 \mathrm{~mm}$, but are completely dry when considering loam. Also, other inundated areas in El Gouna have been documented by photographs and confirmed by shop owners. These inundated areas are not represented in the case of loam as the water directly infiltrates, while they are captured to a certain extent when considering sand with a crust. When comparing the results from different friction coefficients, the significant effect of the friction becomes obvious, as the flood wave from Wadi Bili propagates much slower, and therefore more infiltration can take place leading to overall smaller water depth. This becomes even clearer in Fig. 16, where the temporal development of water depth at the location indicated with a red circle in Fig. 15 is shown for different simulations. While the effect of friction is less pronounced when no infiltration is considered, it gets more important when considering either infiltration for loam or for sand with a surface crust of $5 \mathrm{~mm}$. With a friction coefficient of $n=0.02 \mathrm{sm}^{-1 / 3}$, the peak water depth for sand with crust (orange line with rectangles in Fig. 14) is about $60 \%$ smaller compared to the result with $n=$ $0.01 \mathrm{sm}^{-1 / 3}$ (purple line with triangles in Fig. 16) and occurs about three hours later. For loam, the peak water depth with $n=0.02 \mathrm{sm}^{-1 / 3}$ (dark blue dashed line in Fig. 16) is about 58 $\%$ smaller and 10 hours later than with $n=0.01 \mathrm{sm}^{-1 / 3}$ (light blue line with crosses in Fig. 16). For the consideration of sand with a crust, the infiltration in the first hours of simulation time is lower compared to loam, so that the local rainfall around that location already generated some surface runoff leading to water depths of a few centimeters at the considered location before the flood wave reaches the location.

Shortly after the flood wave has passed the location, the water depth drops to zero, which can be explained by the fact that the wetted depth increased so that the impact of the hydraulic conductivity of the underlying sand is dominating rather than the one of the surface crust. When considering loam, which has a lower hydraulic conductivity than sand but a higher one than the clay of the crust, the infiltration in the beginning is much higher and almost no surface runoff is generated by the local rainfall, as almost all water directly infiltrated. In the case of a friction coefficient of $n=0.01 \mathrm{sm}_{-1 / 3}$, the peak water
Fig. 15 Water depth distributions in the model domain after 9 hours of simulation time considering different values for Infiltration and friction parameteters. Zc: crust thickness, Kc: hydraulic conductivity of crust, Kclay: hydraulic conductivity for clay after Rawls et al. [1], see Table 1, n: Manning 's friction coefficient (background map: (O)penStreetMap contributors) sand with crust, $\mathrm{Zc}=5 \mathrm{~mm}, \mathrm{Kc}=\mathrm{Kclay,} \mathrm{n}=0.01 \mathrm{sm}-1 / 3$

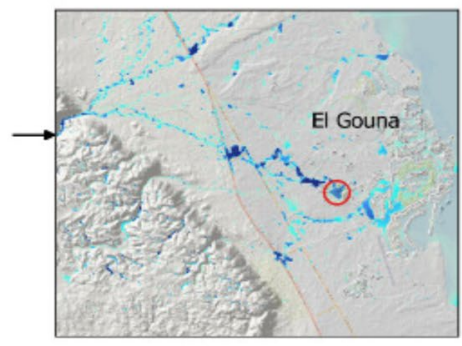

sand with crust, $\mathrm{Zc}=5 \mathrm{~mm}, \mathrm{Kc}=\mathrm{Kclay}, \mathrm{n}=0.02 \mathrm{sm}-1 / 3$

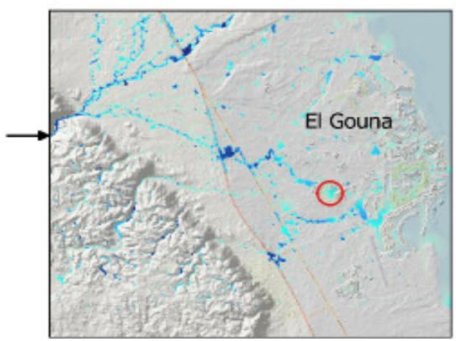

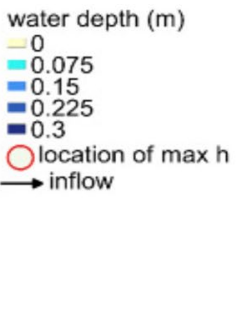

loam, $\mathrm{n}=0.01 \mathrm{sm}^{-1 / 3}$

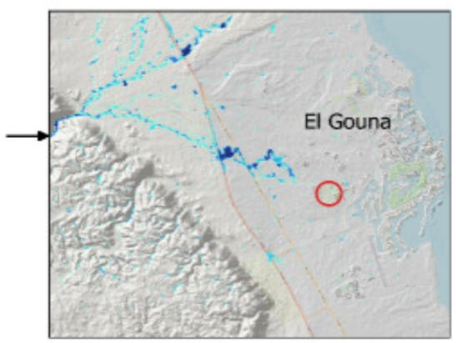

loam, $\mathrm{n}=0.02 \mathrm{sm}^{-1 / 3}$
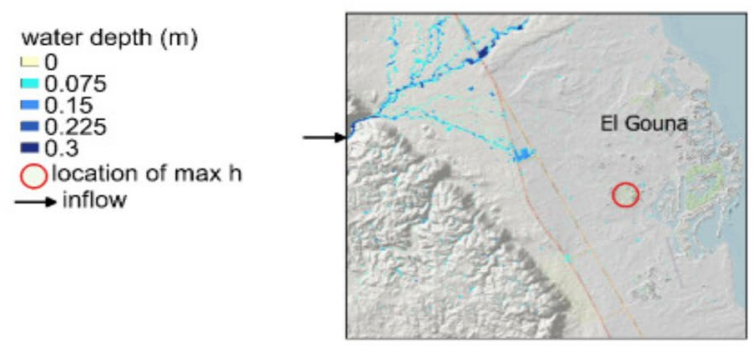
Fig. 16 Temporal development of simulated water depths at location of maximum water depth indicated with a red circle in Fig. 15, considering different infiltration settings and values of Manning 's friction coefficient. K: hydraulic conductivity, Kc: hydraulic conductivity of crust, n: Manning's friction coefficient in $\mathrm{sm}^{-1 / 3}$

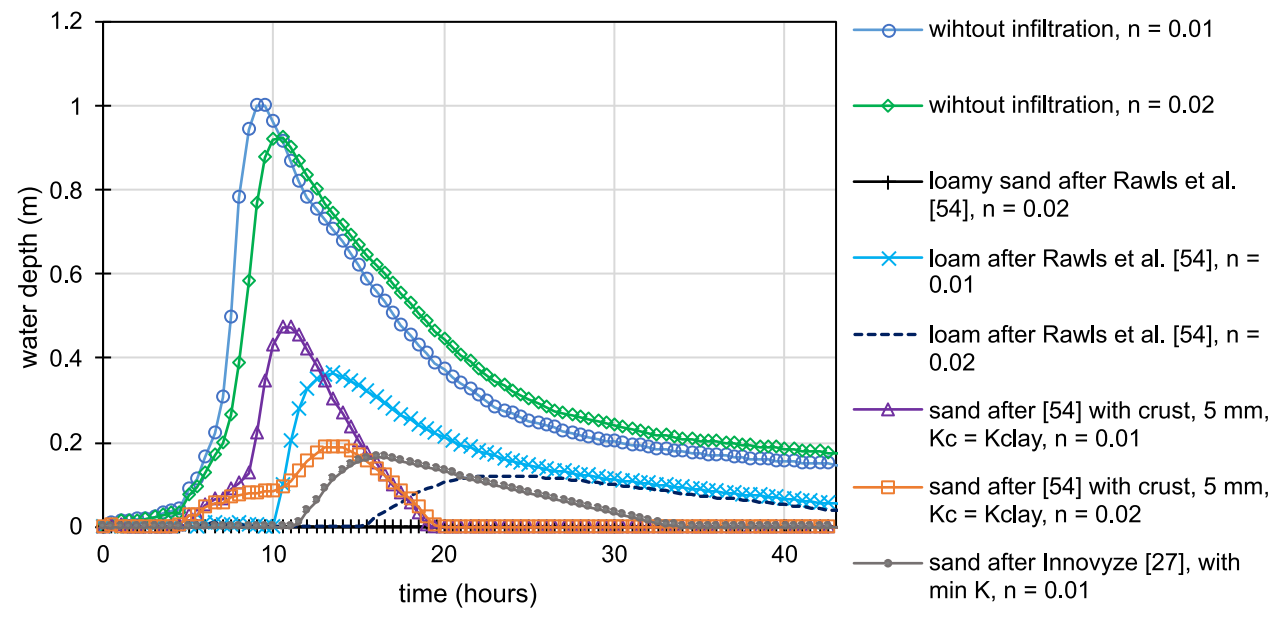

depth occurs about three hours later for loam than for sand with crust and is about $23 \%$ smaller. On the other hand, the water stays much longer at the location also after the flood wave is over, which is due to the higher volume of water that infiltrated already at the beginning causing a faster saturation of the soil. As the hydraulic conductivity is the limiting factor when the saturation increased and the capillary suction has no strong influence anymore, the water from the flood wave infiltrates much slower than in the case of sand with crust, where at later time steps the effective hydraulic conductivity is dominated by the one of the sand below the crust. Taking into account the values for sand after Innovyze with the minimum value for the hydraulic conductivity (grey line with dots in Fig. 16) results in a peak water depth of $16 \mathrm{~cm}$ after about 15.5 hours, which is much more plausible than the result for average values for sand and loamy sand after Rawls et al. [1] (black line with plus signs in 16), where no water depth occurred at the considered location. But similar to the case of loam, the local rainfall around that location directly infiltrated, so that only the flood wave coming from Wadi Bili generated water depths, while the flooding areas induced from the locally fallen rainfall is not captured, and infiltration is therefore still overestimated. On the other hand, similar to the results for loam, the water stays for a longer time after the flood and rainfall event, which in turn agrees better with the observations than the results of sand with a crust, where the water depth drops to zero almost directly after the flood wave has passed. Therefore, a combination of the average values after Innovyze [2] combined with a thin surface crust of lower hydraulic conductivity could lead to the overall most plausible results.

\subsection{Percentual Differences of Optimum Values from Average Values after Rawls et al. [1]}

Figure 14 shows the improvements of the Nash-Sutcliffe efficiency as well as the corresponding percental changes of initial soil moisture deficit $(\Delta \theta)$, hydraulic conductivity (K) and capillary suction head at the wetted front $\left(h_{\mathrm{f}}\right)$ for the two best performing parameter sets of each test case when compared to the average values after Rawls et al. [1], called reference simulation in the following. The NSE could be significantly improved by $112 \%$ and $123 \%$ for Test 1 , 211 and $212 \%$ for Test 2 and by even 586 and $568 \%$ for Test 4 , while the improvement for Test 3 was with $20 \%$ and $16 \%$ much lower as the reference simulation already gave relatively good results.

As a result of the automatic calibration, the initial soil moisture deficit negligibly decreased in both shown parameters sets for the laboratory experiment after Smith and Woolhiser [61] (Test 1). The hydraulic conductivity was fixed in the case where the automatic calibration was carried out within the ranges for sand after Rawls et al. [1] (see Table 1), and decreased by $36 \%$ when calibration was carried out within the ranges for loamy sand to sand after Rawls et al. [1]. The capillary suction head at the wetted front significantly increased in both parameter sets leading to higher infiltration rates, and therefore better results as the overall infiltration was underestimated in the reference simulation. In the case of lower hydraulic conductivity, it increased by $286 \%$ and therefore much stronger than with a fixed hydraulic conductivity (59\%), balancing the reduced hydraulic conductivity and resulting in a similar infiltration as with the higher hydraulic conductivity.

For the two laboratory experiments after Lima [74] (Test 2 and 3), the initial soil moisture deficit slightly increased leading to an increased infiltration, while the initial soil water content was fixed (taken from measurements from Lima [74]), meaning that effectively the saturated soil water content increased. The hydraulic conductivity was not calibrated but fixed either according to the value after Rawls et al. [1] for the given soil type (no change compared to the reference simulation) or after Lima [74] respectively, where it was $77 \%$ higher in Test 2 and $59 \%$ lower in Test 3 
compared to the reference simulations. As infiltration was strongly underestimated in the reference simulation of Test 2 , the capillary suction head strongly increased by $506 \%$ in the case of the same hydraulic conductivity, and still significantly increased by $242 \%$ in the case of higher hydraulic conductivity, leading to a stronger infiltration than in the reference simulation. In Test 3 , the capillary suction head also increased in both cases, while it is higher in the case of decreased hydraulic conductivity ( $310 \%$ compared to $129 \%)$.

For the experiment in the Thiès catchment (Test 4), the initial soil moisture deficit slightly decreased as a result of the automatic calibration leading to less infiltration as in the reference simulation where infiltration was strongly overestimated. Using the fixed values after Innovyze [2] led to an increase of the initial soil moisture deficit by 57 $\%$ compared to the reference simulation. The hydraulic conductivity was strongly reduced by $86 \%$ in the case of automatic calibration, while the lower bound of the calibration range was decreased according to the calibrated value after Simons [59]. When the fixed value of the maximum hydraulic conductivity for sand after Innovyze [2] was used, it was decreased by $90 \%$ compared to the reference simulation, therefore infiltration induced by hydraulic conductivity was reduced in both cases. Remarkably, the capillary suction head was strongly increased by $288 \%$ during calibration and by $105 \%$ with the fixed value after Innovyze [2], causing an enhanced capillary suction induced infiltration compared to the reference simulation. But the overall infiltration (dependent on initial soil moisture deficit, hydraulic conductivity, and capillary suction) was less than in the reference simulation and therefore led to significantly improved results represented by much higher values of NSE. The fact that for all test cases two considerably different parameter sets led to similar results and therefore similar values of NSE emphasizes again the problem of equifinality during the calibration process, which makes it difficult to give clear recommendations for the single parameters.

In the case study about flash floods in Egypt, a reduction of the hydraulic conductivity by $97 \%$ combined with an increase of the capillary suction head by $80 \%$ (corresponding to the average parameters after Rawls et al. [1] for loam), led to much more plausible results of inundation areas and water depths than with the average parameters after Rawls et al. [1] for the dominant soil type sand.

As shown in Test 4, choosing the values after Innovyze [2] considering the maximum hydraulic conductivity improved the NSE by $568 \%$ compared to the average values after Rawls et al. [1]. In Test 2 and 3, the NSE also increased by $162 \%$ and $8 \%$, respectively, when the fixed values after Innovyze [2] with the maximum hydraulic conductivity were chosen instead of the average values after Rawls et al. [1] (not represented in Fig. 17). Hence, it can be concluded that the literature values after Innovyze [2] might be generally more suitable to estimate the Green-Ampt parameters in ungauged areas than the average values after Rawls et al. [1]. In the case study about flash floods in El Gouna (see 3.6), the values for sand after Innovyze [2] under consideration of the lowest value for the hydraulic conductivity led to much more plausible results than the average values for sand after Rawls et al. [1]. As using the maximum value instead of the mean value for the hydraulic conductivity after Innovyze [2] resulted in a better performance for the Test cases 2, 3 and 4, it could be concluded to better choose the hydraulic conductivity within the upper part of the range after Innovyze [2] (according to Akan [67]). On the other hand, the results of the case study in El Gouna showed, that even when choosing the lowest value for the hydraulic conductivity after Innovyze [2] infiltration was still overestimated. Overall, according to the presented results, the values after Innovyze [2] can be rather recommended than the ones after Rawls et al. [1], while the selection of the hydraulic conductivity should be checked individually according to the plausibility of the results for each considered case.

\subsection{Overview of Calibrated Parameter Sets for All Cases}

Table 12 summarizes the optimum parameter sets resulting from the calibration process in test cases 1-4 and the plausibility analysis for the case study in El Gouna. For the case study of El Gouna, the given parameter set did still not lead to satisfying results, as no flooding areas from the local rainfall have been simulated although they have been observed by the community.

\section{Discussion}

The result of the different test cases as well as the case study in Egypt emphasized that taking into account the average values for the Green-Ampt parameters after Rawls et al. [1] does often not lead to appropriate results. In the laboratory experiments after Smith and Woolhiser [61] for sandy soil and after Lima [74] for loam, the average values after Rawls et al. [1] led to a significant underestimation of infiltration, while in the field experiment in the Thiès catchment in Senegal as well as in the case study in Egypt, they strongly overestimated infiltration, resulting in no surface runoff which is not representing the observed incidents. For the second laboratory experiment after Lima [74] for clay loam, the simulation with average Green-Ampt parameters after Rawls et al. [1] resulted in a relatively good agreement to the observations. When considering the typical values for the Green-Ampt parameters after Innovyze [2], the results for the experiment after Lima [74] for loamy soil as well 
Fig. 17 Percental changes of the Green-Ampt (GA) parameters for each test case compared to the average values after Rawls et al. [1]. NSE: Nash-Sutcliffe efficiency, $\Delta \theta$ : initial soil moisture deficit, K: hydraulic conductivity, $h_{\mathrm{f}}$ : capillary suction head and wetted front, $\mathrm{n}$ : Manning's friction coefficient, max K: maximum hydraulic conductivity after Innovyze [2] according to Akan [67] (see Table 2)

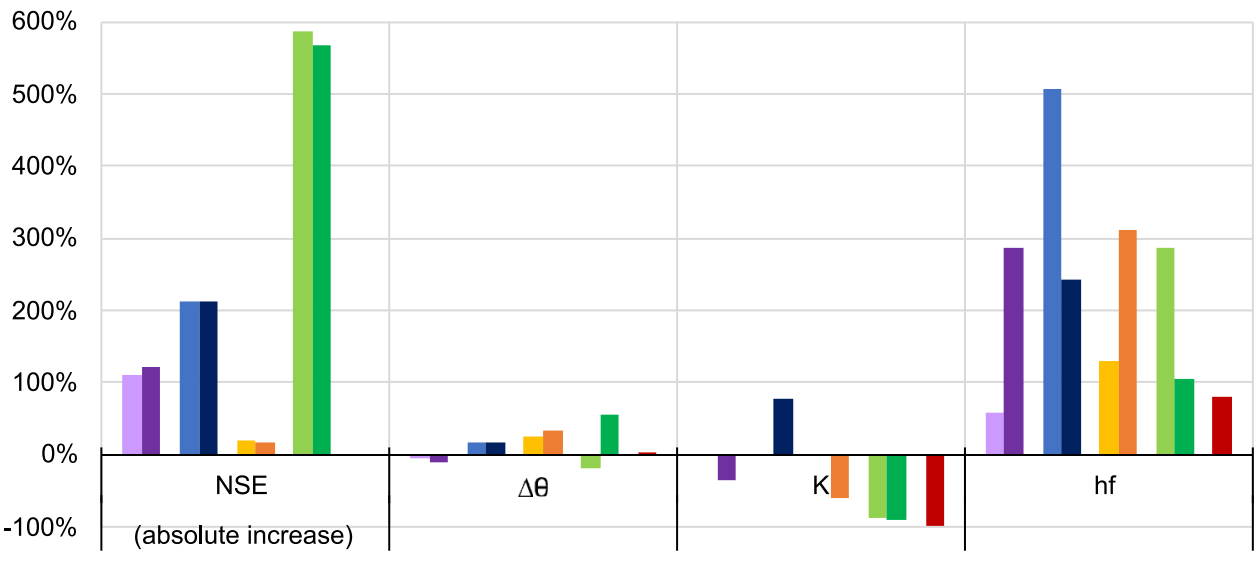

Test 1 - hf and $\Delta \theta$ calibrated in ranges for sand after Rawls et al. [54]

- Test 1 - hf, $\Delta \theta$ and $\mathrm{K}$ calibrated in ranges for loamy sand - sand (Rawls)

- Test 2 - hf and $\Delta \theta$ calibrated in ranges for loam after Rawls et al. [54]

- Test 2 - values after Lima [35], hf calibrated

After Smith and Woolhiser [64]

After Lima [35] (a)

- Test 3 - calibrated in ranges for clay loam after Rawls et al. [54]

- Test 3 - values after Lima [35], hf calibrated

After Lima [35] (b)

Test 4 - hf, $\Delta \theta$ and $\mathrm{K}$ calibrated in ranges for sand after Rawls [54], lower $\mathrm{K}$

- Test 4 - sand after Innovyze [27] with max K

Thiès catchment

Tatard et al. [66]

- Case study El Gouna with average GA parameter for loam compared to sand

as for the Thiès catchment and the case study in El Gouna for sandy soil were much better than with the average values after Rawls et al. [1]. Nevertheless, infiltration was still underestimated in the experiment after Lima [74] with loamy soil, and also in the experiment in the Thiès catchment in Senegal, while it was still overestimated for El Gouna, even when using the minimum value for the hydraulic conductivity after Akan [67]. The consideration of a surface crust of a few millimeters generated much more plausible results for the first hours of simulation time, while the fast decrease in water depth after the flood event does not represent the real conditions appropriately. Furthermore, it was shown that the effect of friction on the infiltration process can also be significant, especially in larger-scale applications.
As the performance of average Green-Ampt parameters for sand after Rawls et al. [1] for laboratory experiments tend to go in the reverse direction than for field experiments, it could be argued that the conditions of the laboratory experiments did not represent similar conditions as occurring in the field. One reason could be that during the laboratory experiments, the formation of a crust could have been prevented due to covering the soil with gauze as described in the experimental setup of Smith and Woolhiser [61], that protected the soil surface from raindrop impact. In addition, the soil crust in lab experiments would develop gradually due to the rainfall splash, while in field studies the soil crust might have been formed already before the event itself, for example, due to prior rainfall events and other
Table 12 Overview of calibrated parameter sets for all cases

\begin{tabular}{|c|c|c|c|c|c|c|c|}
\hline Case & Texture class & $\theta_{\mathrm{i}}\left(\mathrm{m}^{3} / \mathrm{m}^{3}\right)$ & $\theta_{\mathrm{s}}\left(\mathrm{m}^{3} / \mathrm{m}^{3}\right)$ & $\mathrm{K}(\mathrm{cm} / \mathrm{h})$ & $h_{\mathrm{f}}(\mathrm{cm})$ & Friction & NSE (-) \\
\hline Test case 1 & Sand & 0.123 & 0.425 & 7.56 & 18.90 & $C_{\mathrm{lam}} 1328383 \mathrm{~m}^{-1} \mathrm{~s}^{-1}$ & 0.984 \\
\hline Test case 2 & Loam & 0.0107 & 0.503 & 0.34 & 53.90 & Manning $0.021 \mathrm{sm}^{-1 / 3}$ & 0.928 \\
\hline Test case 3 & Clay loam & 0.006 & 0.390 & 0.10 & 47.90 & Manning $0.033 \mathrm{sm}^{-1 / 3}$ & 0.924 \\
\hline Test case 4 & Sand & 0.200 & 0.378 & 1.62 & 19.20 & $\begin{array}{c}\mathrm{n} 0: 0.014 \mathrm{sm}^{-1 / 3} \mathrm{~h} 0: \\
0.0045 \mathrm{~m} \varepsilon: 0.1^{*}\end{array}$ & 0.810 \\
\hline Case study & Sand, loam & 0.03 & 0.434 & 0.34 & 8.89 & Manning $0.01 \mathrm{sm}^{-1 / 3}$ & - \\
\hline
\end{tabular}

$\theta_{\mathrm{i}}$ : initial soil water content, $\theta_{\mathrm{s}}$ : effective porosity, $\mathrm{K}$ : hydraulic conductivity; $h_{\mathrm{f}}$ : capillary suction at wetted front;

*depth-dependent Manning's law 
processes. Furthermore, it might have been the case that in the lab experiment the soil was more homogenous so that no finer particles could lead to clogging of the pores. On the other hand, the trend to overestimate infiltration by average Green-Ampt parameters after Rawls et al. [1] under natural and field conditions was studied here only for sandy soils in semi-arid to arid areas. Case studies in areas with different soil texture classes as well as other climate conditions might lead to other results.

Prado Hernández et al. [83] investigated six different texture classes from loam to clay in Mexico and compared different approaches to estimate the Green-Ampt parameters with measured infiltration rates from double-ring infiltrometer tests. Their results show a strong underestimation of infiltration when considering the average values after Rawls et al. [1]. This observation agrees well with the results from the laboratory experiments after Smith and Woolhiser [61] as well as Lima [74] for loam, where infiltration with average values after Rawls et al. [1] was also strongly underestimated. On the other hand, ponded infiltration rates as measured with double-ring infiltrometers tend to be higher than the actual infiltration rates during natural or simulated rainfall events [50, 84]. Therefore, it might be questionable to evaluate the results from the Green-Ampt model with the ponded infiltration rates from double-ring infiltrometer tests, when the aim is to estimate infiltration during rainfalls. In other studies, such as Xiang et al. [36], the Green-Ampt parameters were derived from rainfall simulator tests, where the observed infiltration probably agrees better with the one during natural rainfalls than the ponded infiltration measured from double-ring infiltrometer test.

\section{Conclusions and Outlook}

A robust depth-averaged 2D shallow water model incorporating the Green-Ampt model for infiltration was used to study the performance of tabulated values for the Green-Ampt parameters taken from different sources in the literature. For one test case, a sensitivity analysis for the Green-Ampt, crust and friction parameters was carried out. The results show that the hydraulic conductivity, the capillary suction at the wetted front, and the initial soil moisture as well as the crust conductivity, crust thickness and matric potential drop at the crust/subcrust interface significantly affect the infiltration and therefore the surface runoff. Afterwards, four different test cases with observed data to enable an evaluation of model results as well as one real-world application in an ungauged area were investigated, where average values for different soil texture classes after Rawls et al. [1] on the one hand and after Innovyze [2] on the other hand resulted in different performances. The average values after Rawls et al. [1] led to underestimations of infiltration in laboratory experiments with sandy and loamy soil, respectively, while showing a relatively good agreement in a laboratory experiment with clay loam, and strongly overestimated infiltration in a field experiment in Senegal as well as in a case study in Egypt, both with almost bare sandy soil. For the laboratory experiment with loam, the field experiment in Senegal and the case study in Egypt, the values after Innovyze [2] resulted in better performances than the ones after Rawls et al. [1], while they strongly underestimated infiltration in the laboratory experiment after Smith and Woolhiser [61], still underestimated the infiltration for the experiment with loam, and also for the field experiment in Senegal, and overestimated the infiltration in the case study in Egypt. Based on the obtained results for the two cases in real catchments with sandy soil (Test 4 in Thiès catchment, Senegal and the Case study El Gouna, Egypt), it is recommended to use lower values for the hydraulic conductivity than the values for sand given in Rawls et al. [1] to prevent an overestimation of infiltration. In both cases, the hydraulic conductivity was decreased by about $90-100 \%$, while the capillary suction head at the wetted front was increased by about $80-288 \%$ compared to the average values after Rawls et al. [1]. Despite of this strong increase of the capillary suction, which enhances infiltration particularly at early time steps when the soil moisture deficit is high, the overall infiltration rates are much smaller and more realistic than the ones with average values. This emphasizes the stronger sensitivity of surface runoff on the hydraulic conductivity than on the capillary suction.

Overall, it can be recommended to use the values after Innovyze [2] rather than the average values after Rawls et al. [1] as they led to better results in all studied cases except for the laboratory experiment after Smith and Woolhiser [61] (Test case 1). If the given soil of the considered study area might tend to form a surface crust during heavy rainfalls, as it is, for example, the case for bare soils in arid areas, a thin layer of a few millimeters with reduced hydraulic conductivity to account for this crust and the application of an effective hydraulic conductivity between the crust and subcrust soil, might be suitable to represent the infiltration behavior more realistically. But in the represented results, this approach also led to an overestimation of infiltration at later times steps if the parameter values of the subcrust soil are taken from Rawls et al. [1]. As for both cases in natural areas (in Senegal and Egypt) the soil texture class was sand, further investigations should be carried out for field tests with other soil texture classes to give recommendations also for ungauged areas with other dominant soil texture classes.

Currently, a study on simulating the rainfall simulator experiments represented in Ries et al. [28] is carried out to evaluate the performance of the tabulated Green-Ampt parameters for different land use and soil types. For the case study in Egypt, it is planned to carry out rainfall simulator tests to 
get a better estimation of the infiltration behavior occurring during natural rainfall events in that area. Through measuring the surface runoff and soil moistures, as well as recording the plot areas with digital photos to generate high-resolution DEMs using photogrammetry, the plot-scale field tests can be simulated and calibrated afterwards to derive appropriate Green-Ampt parameters for the model area. Furthermore, the possibly occurring surface sealing as well as microtopography and their effect on infiltration will be studied, in addition to the influence of the DEM resolution on modeling infiltration. The overall aim is to define the most important determinants that influence infiltration under different circumstances and to find suitable values of Green-Ampt parameters for different cases.

Acknowledgements The simulations have been partially carried out on the supercomputers from the HPC-cluster of TU Berlin and partially on the supercomputers of HLRN (Norddeutscher Verbund für Hoch-und Hüchstleistungsrechnen).

Author Contributions F. Tügel and R. Hinkelmann designed the framework for the publication. F. Tügel performed the computations and analyzed the results. Furthermore, she collected the data of the experiments from the literature. A. Hassan supported the calibration process by using optimization methods and developed the code for the automatic calibration. F. Tügel wrote the manuscript with support from R. Hinkelmann and J. Hou. All authors discussed the results and contributed to the final manuscript.

Funding Open Access funding enabled and organized by Projekt DEAL. This work was supported by the Technische Universität Berlin and the DFG Research Training Group "UrbanWater Interfaces" (GRK 2032/2)

Data Availability Data and material can be provided on request.

Code Availibility The full source code of hms is available at https:// gitlab.tu-berlin.de/hms. Access to the GIT repository is granted by the Chair of Water Resources Management and Modeling of Hydrosystems, Technische Universität Berlin, Germany and Modeling of Hydrosystems, Technische Universität Berlin, Germany.

\section{Declarations}

Conflicts of Interest On behalf of all authors, the corresponding author states that there is no conflict of interest.

Open Access This article is licensed under a Creative Commons Attribution 4.0 International License, which permits use, sharing, adaptation, distribution and reproduction in any medium or format, as long as you give appropriate credit to the original author(s) and the source, provide a link to the Creative Commons licence, and indicate if changes were made. The images or other third party material in this article are included in the article's Creative Commons licence, unless indicated otherwise in a credit line to the material. If material is not included in the article's Creative Commons licence and your intended use is not permitted by statutory regulation or exceeds the permitted use, you will need to obtain permission directly from the copyright holder. To view a copy of this licence, visit http://creativecommons.org/licenses/by/4.0/.

\section{References}

1. Rawls, W. J., Brakensiek, D. L., \& Miller, N. (1983). Green-Ampt infiltration parameters from soils data. Journal of Hydraulic Engineering, 1, 62-70. https://doi.org/10.1061/(ASCE)07339429(1983)109:1(62)

2. Innovyze. (2019). Help documentation of XPSWMM and XPStorm. https://help.innovyze.com/display/xps/Infiltration, accessed 30 Apr 2020.

3. Caviedes-Voulliéme, D., Murillo, J., \& Garcia-Navarro, P. (2012). Influence of mesh structure on $2 \mathrm{D}$ full shallow water equations and SCS Curve Number simulation of rainfall/runoff events. Journal of Hydrology, 448-449, 39-59.

4. Liang, Q., Xia, X., \& Hou, J. (2016). Catchment-scale high-resolution flash flood simulation using the GPU-based technology. Procedia Engineering 154, 975-981. https://doi.org/10.1016/j.proeng.2016. 07.585

5. Mügler, C., Planchon, O., Patin, J., Weill, S., Silvera, N., Richard, P., \& Mouche, E. (2011). Comparison of roughness models to simulate overland flow and tracer transport experiments under simulated rainfall at plot scale. Journal of Hydrology, 402, 25-40.

6. Simons, F., Busse, T., Hou, J., Özgen, I., \& Hinkelmann, R. (2014). A Model for overland flow and associated processes within the Hydroinformatics Modelling System. Journal of Hydroinformatics 16(2), 375-391. https://doi.org/10.2166/hydro. 2013.173

7. Viero, D. P., Peruzzo, P., Carniello, L., \& Defina, A. (2014). Integrated mathematical modeling of hydrological and hydrodynamic response to rainfall events in rural lowland catchments. Water Resources Research 50, 5941-5957. https://doi.org/10.1002/ 2013WR014293

8. Abderrezzak, K. E., Paquier, A., \& Mignot, E. (2009). Modelling flash flood propagation in urban areas using a two-dimensional numerical model. Natural Hazards, 50, 433-460.

9. Broich, K., Pflugbeil, T., Disse, M., \& Nguyen, H. (2020). Using TELEMAC-2D for hydrodynamic modeling of rainfall-runoff. Zenodo, Toulouse. http://doi.org/10.5281/zenodo.3611524

10. Huang, W., Cao, Z., Huang, M., Duan, W., Ni, Y., \& Yang, W. (2019). A new flash flood warning scheme based on hydrodynamic modelling. Water 11(6), 1221. https://doi.org/10.3390/ w11061221

11. Tügel, F., Özgen-Xian, I., Marafini, E., Hadidi, A., \& Hinkelmann, R. (2020a). Flash flood simulations for an Egyptian city-mitigation measures and impact of infiltration. Urban Water Journal 17(5), 396-406. https://doi.org/10.1080/1573062X.2020.1713171

12. Cui, Y., Liang, Q., Wang, G., Zhao, J., Hu, J., Wang, Y., \& Xia, X. (2019). Simulation of hydraulic structures in 2D high-resolution urban flood modeling. Water 11(10), 2139. https://doi.org/10.3390/ w11102139

13. Leandro, J., Schumann, A., \& Pfister, A. (2016). A step towards considering the spatial heterogeneity of urban key features in urban hydrology flood modelling. Journal of Hydrology, 535, 356-365.

14. Roland, A., Rausch, R., Huxhorn, T., Kraus, T., Wallisch, S., Sikiric, M. D., et al. (2015). Hochauflösende Simulation von urbanen Sturzfluten Anwendungsbeispiel: Überflutungsprüfung für die Stadt Worms. Korrespondenz Abwasser, Abfall, 62(3), $215-224$.

15. Xing, Y., Liang, Q., Wang, G., Ming, X., \& Xia, X. (2019). Cityscale hydrodynamic modelling of urban flash floods: the issues of scale and resolution. Natural Hazards 96, 473-496. https://doi. org/10.1007/s11069-018-3553-z 
16. Fernández-Pato, J., Caviedes-Voulliéme, D., \& García-Navarro, P. (2016). Rainfall/runoff simulation with 2D full shallow water equations: Sensitivity analysis and calibration of infiltration parameters. Journal of Hydrology 536, 496-513. https://doi.org/ 10.1016/j.jhydrol.2016.03.021

17. Assouline, S., \& Mualem, Y. (2006). Runoff from heterogeneous small bare catchments during soil surface sealing. Water Resources Research 42, W12405. https://doi.org/10.1029/ 2005WR004592

18. Klove, B., Ala-Aho, P., Bertrand, G., Gurdak, J. J., Kupfersberger, H., Kværner, J., \& Muotka, T. (2014). Climate change impacts on groundwater and dependent ecosystems. Journal of Hydrology 518(Part B), 250-266. https://doi.org/10.1016/j.jhydrol.2013.06.037

19. Miller, J. D., \& Hutchins, M. (2017). The impacts of urbanisation and climate change on urban flooding and urban water quality: A review of the evidence concerning the United Kingdom. Journal of Hydrology: Regional Studies 12, 345-362. https://doi.org/10. 1016/j.ejrh.2017.06.006

20. Ghazal, A. (2018). Urban flood protection in Arid Regions King Fahd Suburb in Dammam-Saudi Arabia. Master's thesis, TU Berlin Campus El Gouna. Water Engineering.

21. Vergroesen, T., \& Verschelling, E. (2014). Becker B Modelling of sustainable urban drainage measures. Revista de Ingeniería Innova, 8, 1-16.

22. Eric, M., Fan, C., Joksimovic, D., \& Li, J. Y. (2013). Modeling low impact development potential with hydrological response units. Water Science and Technology 68(11), 2382-2390. https:// doi.org/10.2166/wst.2013.502

23. Kong, F., Ban, Y., Yin, H., James, P., \& Dronova, I. (2017). Modeling stormwater management at the city district level in response to changes in land use and low impact development. Environmental Modelling and Software 95, 132-142. https://doi.org/10. 1016/j.envsoft.2017.06.021

24. Palla. A., \& Gnecco, I. (2015). Hydrologic modeling of low impact development systems at the urban catchment scale. Journal of Hydrology 528, 361-368. https://doi.org/10.1016/j.jhydrol. 2015.06.050

25. Hendrickx, J. M., \& Walker, G. (1997). Recharge from Precipitation, Chapter 2. In I. Simmers (Ed.), Recharge of Phreatic Aquifers in (Semi)-Arid Areas. Taylor and Francis, Balkema, Rotterdam: IAH Contributions to Hydrogeology Series.

26. Mu, W., Yu, F., Li, C., Xie, Y., Tian, J., Liu, J., \& Zhao, N. (2015). Effects of rainfall intensity and slope gradient on runoff and soil moisture content on different growing stages of spring maize. Water, 7, 2990-3008.

27. Nassif, S. H., \& Wilson, E. M. (1975). The influence of slope and rain intensity on runoff and infiltration. Hydrological Sciences Bulletin 20(4), 539-553. https://doi.org/10.1080/02626667509491586

28. Ries, F., Kirn, L., \& Weiler, M. (2020). Experimentelle Untersuchung der Abflussbildung bei Starkregen, Hydrologie und Wasserbewirtschaftung 64(5), 221-236. https://doi.org/10.5675/HyWa_ 2020.5

29. Ribolzi, O., Patin, J., Bresson, L. M., Latsachack, K., Mouche, E., Sengtaheuanghoung, O., et al. (2011). Valentin C Impact of slope gradient on soil surface features and infiltration on steep slopes in northern Laos. Geomorphology, 127, 53-63.

30. Mohammadzadeh-Habili, J., \& Heidarpour, M. (2015). Application of the Green-Ampt model for infiltration into layered soils. Journal of Hydrology 527, 824-832. https://doi.org/10.1016/j. jhydrol.2015.05.052

31. Deng, P., \& Zhu., J. (2016). Analysis of effective Green-Ampt hydraulic parameters for vertically layered soils. Journal of Hydrology 538, 705-71. http://dx.doi.org/10.1016/j.jhydrol.2016.04.059

32. Esteves, M., Faucher, X., Galle, S., \& Vauclin, M. (2000). Overland flow and infiltration modelling for small plots during unsteady rain: Numerical results versus observed values.
Journal of Hydrology 228(3-4), 265-282. https://doi.org/10. 1016/S0022-1694(00)00155-4

33. Fiedler, F. R., Ramirez, J. A. (2000). A numerical method for simulating discontinuous shallow flow over an infiltrating surface. International Journal for Numerical Methods in Fluids 32, 219-239. https://doi.org/10.1002/(SICI)1097-0363(20000130) $32: 2<219::$ AID-FLD936>3.0.CO;2-J

34. Mallari, K. J. B., Kim, H., Pak, G., Aksoy, H., \& Yoon, J. (2015) A comparison of two infiltration models applied to simulation of overland flow over a two-dimensional flume. Water Science and Technology 71(9), 1325-1332. https://doi.org/10.2166/wst. 2015.060

35. Thompson, S. E., Katul, G. G., \& Porporato, A. (2010). Role of microtopography in rainfall-runoff partitioning: An analysis using idealized geometry. Water Resources Research 46, W07520. https://doi.org/10.1029/2009WR008835

36. Xiang, L., Ling, W., Zhu, Y., Chen, L., \& Yu, Z. (2016). Selfadaptive Green-Ampt infiltration parameters obtained from measured moisture processes. Water Science and Engineering 9(3), 256-264. https://doi.org/10.1016/j.wse.2016.05.001

37. Farthing, M. W., \& Ogden, F. L. (2017). Numerical solution of Richards' equation: a review of advances and challenges. Soil Science Society of America Journal, 81, 1257-1269.

38. Turner, E. R. (2006). Comparison of infiltration equations and their field validation with rainfall simulation. M.sc Thesis, Department of Biological Resources Engineering, Faculty of the Graduate School of the University of Maryland, College Park.

39. Chen, L., Xiang, L., Young, M. H., Yin, J., Yu, Z., \& Genuchten, M. (2015). Optimal parameters for the Green-Ampt infiltration model under rainfall conditions. Journal of Hydrology and Hydromechanics 63(2), 93-101. https://doi.org/10.1515/johh-2015-0012

40. Rawls, W. J., \& Brakensiek, D. L. (1989). Estimation of soil water retention and hydraulic properties. In H. J. Morel-Seytoux (Ed.), Unsaturated Flow in Hydrologic Modeling-Theory and Practice, pp 275-300. Dordrecht: Springer.

41. Green, W. H., \& Ampt, G. A. (1911). Studies on soil physics, Part 1, the flow of air and water through Soils. The Journal of Agricultural Science 4, 11-24.

42. Mein, R. G., \& Larson, C. L. (1971). Modeling the infiltration component of the rainfall-runoff process. Minneapolis, Minnesota: Water Resources Research Center.

43. Ni, Y., Cao, Z., Liu, Q., \& Liu, Q. (2020). A 2D hydrodynamic model for shallow water flows with significant infiltration losses. Hydrological Processes 34, 2263-2280. https://doi.org/10.1002/ hyp. 13722

44. Van Mullem, J. A. (1989). Applications of the Green-Ampt infiltration model to watersheds in Montana and Wyoming. Montana State University.

45. Stadler, L. (2016). Entwicklung von Modellkonzepten für die Simulation von Zweiphasenströmungen in makroporösen Böden, $\mathrm{PhD}$ thesis, Technische Universität Berlin.

46. Schaap, M. G., Leij, F. J., \& van Genuchten, M. T. (2001). Rosetta: a computer program for estimating soil hydraulic parameters with hierarchical pedotransfer functions. Journal of Hydrology, 251, 163-176.

47. Twarakavi, N. K. C., Šimunek, J., \& Schaap, M. G. (2010). Can texture-based classification optimally classify soils with respect to soil hydraulics? Water Resources Research 46, W01501. https:// doi.org/10.1029/2009WR007939

48. Van den Putte, A., Govers, G., Leys, A., Langhans, C., Clymans, W., \& Diels, J. (2013). Estimating the parameters of the GreenAmpt infiltration equation from rainfall simulation data: Why simpler is better. Journal of Hydrology 476, 332-344. https://doi.org/ 10.1016/j.jhydrol.2012.10.051

49. Morin, J., \& Benyamini, Y. (1977). Rainfall infiltration into bare soils. Water Resources Research 13(5), 813-817. https://doi.org/ 10.1029/WR013i005p00813 
50. Müller, E. N. (2007). Scaling approaches to the modelling of water, sediment and nutrient fluxes within semi-arid landscapes, Jornada Basin, New Mexico. Logos Verlag Berlin, ISBN 978-38325-1754-0, PhD thesis submitted 2004 to King's College London, UK.

51. Nciizah, A. D., \& Wakindiki II, C. (2015). Soil sealing and crusting effects on infiltration rate: a critical review of shortfalls in prediction models and solutions. Archives of Agronomy and Soil Science 61(9), 1211-1230. https://doi.org/10.1080/03650340. 2014.998203

52. McIntyre, D. S. (1958). Permeability measurements of soil crusts formed by raindrop impact. Soil Science, 85(4), 185-189.

53. Sharma, M. L., Gander, G. A., \& Hunt, C. G. (1980). Spatial variability of infiltration in a watershed. Journal of Hydrology 45(1-2), 101-122. https://doi.org/10.1016/0022-1694(80)90008-6

54. Tackett, J. L., \& Pearson, R. W. (1965). Soil Science, 99(6), 407-413.

55. Brakensiek, D. L., \& Rawls, W. J. (1983). Agricultural management effects on soil water processes. Part II: Green and Ampt parameters for crusting soils. Transactions of ASAE, 26(6), $1753-1757$.

56. Rawls, W. J., Brakensiek, D. L., Simanton, J. R., \& Kohl, K. D. (1990). Development of a crust factor for a Green Ampt model. Transactions of ASAE 33(4), 1224-1228. https://doi.org/10.13031/ 2013.31461

57. Hassan, A., Özgen, I., \& Hinkelmann, R. (2018). Using a simplextype optimization method to calibrate a hydrodynamic model for rainfall-runoff simulations. Proceedings of the 5th IAHR Europe Congress-New Challenges in Hydraulic Research and Engineering. ISBN: 978-981-11-2731-1.

58. Özgen, I., Simons, F., Zhao, J., \& Hinkelmann, R. (2014). Modeling Shallow Water Flow And Transport Processes With Small Water Depths Using The Hydroinformatics Modelling System. New York: CUNY Academic Works.

59. Simons, F. (2020). A robust high-resolution hydrodynamic numerical model for surface water flow and transport processes within a flexible software framework, $\mathrm{PhD}$ thesis, Technische Universität Berlin. https://henry.baw.de/bitstream/handle/20.500.11970/ 107124/simons_franz.pdf? sequence $=1 \&$ isAllowed $=y$, accessed 30 Apr 2020.

60. Jain, M. K., Kothyari, U. C., \& Ranga Raju, K. G. (2004). A GIS distributed rainfall-runoff model. Journal of Hydrology, 299, 107-135.

61. Smith, R. E., \& Woolhiser, D. A. (1971). Overland flow on an infiltrating surface. Water Resources Research, 7(4), 899-913.

62. Delfs, J. O., Park, C. H., Kolditz, O. (2009). A sensitivity analysis of Hortonian flow. Advances in Water Resources 32(9), 13861395. https://doi.org/10.1016/j.advwatres.2009.06.005

63. Whisler, F., \& Bouwer, H. (1970). Comparison of methods for calculating vertical drainage and infiltration for soils. Journal of Hydrology 1, 1-19. https://doi.org/10.1016/0022-1694(70) 90051-X

64. Chu, X. F., \& Marino, M. A. (2005). Determination of ponding condition and infiltrationinto layered soils under unsteady rainfall. Journal of Hydrology 313(3-4), 195-207. http://dx.doi.org/10. 1016/j.jhydrol.2005.03.002

65. Zhu, J., \& Warrick, A. W. (2012). Unsaturated hydraulic conductivity of repeatedly layered soil structures. Soil Science Society of America Journal 76, 28-35. https://doi.org/10.2136/sssaj2011. 0028

66. Clapp, R. B., \& Hornberger, G. M. (1978). Empirical equations for some soil hydraulic properties. Water Resources Research 14(4), 601-604. https://doi.org/10.1029/WR014i004p00601
67. Akan, A. O. (1993). Urban stormwater hydrology: A guide to engineering calculations. Lancaster, Pennsylvania: Technomic Pub. Co.

68. Abraham, S., Huynh, C., \& Vu, H. (2020). Classification of soils into hydrologic groups using machine learning. Data 5(1), 2. https://doi.org/10.3390/data5010002

69. Musgrave, G. W. (1995). How much of the rain enters the soil? In: Water: U.S. Department of Agriculture Yearbook, United States Government Publishing Office (GPO): Washington, DC, pp. 151-159.

70. Endres, S. C., Sandrock, C., \& Focke, W. W. (2018). A simplicial homology algorithm for Lipschitz optimisation. Journal of Global Optimization 72, 181-217. https://doi.org/10.1007/ s10898-018-0645-y

71. Nash, J. E., \& Sutcliffe J. V. (1970). River flow forecasting through conceptual models part I-A discussion of principles. Journal of Hydrology 10(3), 282-290. https://doi.org/10.1016/00221694(70)90255-6

72. Pool, S., Vis, M., \& Seibert, J. (2018). Evaluating model performance: towards a non-parametric variant of the Kling-Gupta efficiency. Hydrological Sciences Journal 63(13-14), 19411953. https://doi.org/10.1080/02626667.2018.1552002

73. Hallouin, T. (2019). HydroEval: Streamflow Simulations Evaluator (Version 0.0.3), Zenodo. https://doi.org/10.5281/zenodo.2591217

74. Lima, J. L. M. P. (1989). Overland flow under rainfall: some aspects related to modelling and conditioning factores. PhD thesis. Agricultural University Wageningen. https://library.wur.nl/WebQuery/ wurpubs/fulltext/202869, accessed 30 Apr 2020.

75. Tatard, L, Planchon, O., Wainwright, J., Nord, G., Favis-Mortlock, D., Silvera, N., Ribolzi, O., Esteves, M., \& Huang, C. H. (2008). Measurement and modelling of high-resolution flow-velocity data under simulated rainfall on a low-slope sandy soil. Journal of Hydrology 348(1-2), 1-12. https://doi.org/10.1016/j.jhydrol.2007.07.016

76. Park, S., Kim, B., \& Kim, D. H. (2019). 2D GPU-accelerated high resolution numerical scheme for solving diffusive wave equations. Water, 11, 1447

77. Wannous, M., Theilen-Willige, B., Troeger, U., Falk, M., \& Bauer F. (2021). Hydrochemistry and environmental isotopes of spring water and their relation to structure and lithology identified with remote sensing methods in Wadi Araba, Egypt. Hydrogeology Journal. https://doi.org/10.1007/s10040-021-02343-x

78. Hadidi, A. (2016). Wadi Bili catchment in the eastern desert-flash floods, geological model and hydrogeology. Berlin: Fakultät VIPlanen Bauen Umwelt der Technischen Universität Berlin.

79. Engman, E. T. (1986). Roughness coefficients for routing surface runoff. Journal of Irrigation and Drainage Engineering 11(1), 39-53. https://doi.org/10.1061/(ASCE)0733-9437(1986)112: $1(39)$

80. JAXA. (2017). ALOS Global Digital Surface Model "ALOS World 3D-30 m (AW3D30), Japan Aerospace Exploration Agency Earth Observation Research Center. http://www.eorc. jaxa.jp/ALOS/en/aw3d30/index.htm, accessed 20 Feb 2017.

81. Tügel, F., Abdelrahman, A. A. A., Özgen-Xian, I., Hadidi, A., \& Hinkelmann, R. (2020b). Rainfall-runoff modeling to investigate flash floods and mitigation measures in the Wadi Bili catchment, Egypt. In: P. Gourbesville, \& G. Caignaert (Eds.), Advances in hydroinformatics. Springer Water, Springer, Singapore. https:// doi.org/10.1007/978-981-15-5436-0_44

82. FAO. (2019). Harmonized World Soil Database V 1.2. http:// www.fao.org/soils-portal/soil-survey/soil-maps-and-databases/ harmonized-world-soil-database-v12/en/, accessed 17 Jan 2019.

83. Prado Hernandez, J. V., Pascual Ramírez, F., Cristóbal Acevedo, D., Carrillo García, M., \& Martínez Ruíz A. (2016). Determination 
and evaluation of the parameters for the Green \& Ampt infiltration equation in some agricultural soils in Mexico, Preprints, 2016120067. https://doi.org/10.20944/preprints201612.0067.v1

84. Wainwright, J. (1996). Infiltration, runoff and erosion characteristics of agricultural land in extreme storm events, SE France.
Catena 26(1-2), 27-47. https://doi.org/10.1016/0341-8162(95) 00033-X

Publisher's Note Springer Nature remains neutral with regard to jurisdictional claims in published maps and institutional affiliations. 